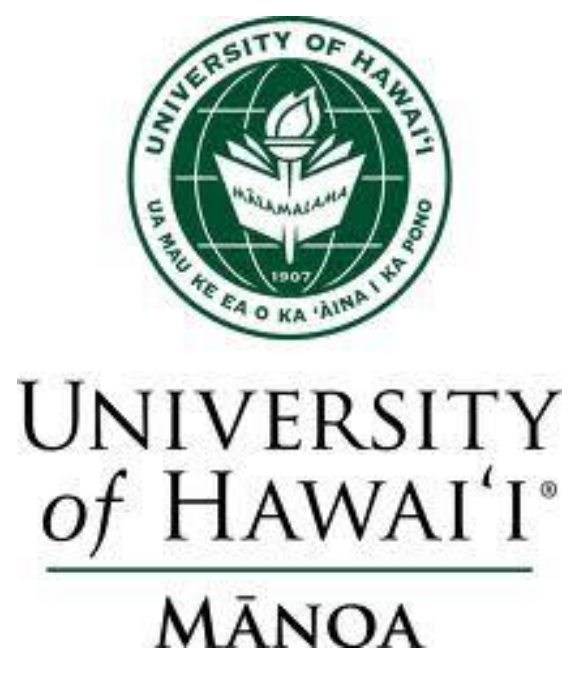

University of Hawai $i$ at Mānoa Department of Economics Working Paper Series

Saunders Hall 542, 2424 Maile Way, Honolulu, HI 96822

Phone: (808) $956-8496$ www.economics.hawaii.edu

\author{
Working Paper No. 16-15R
(Revised Version of WP No. 11-13) \\ Endogenous Search, Price Dispersion, and Welfare
}




\title{
Endogenous Search, Price Dispersion, and Welfare*
}

\author{
Liang Wang ${ }^{\dagger}$ \\ University of Hawaii Manoa
}

August 31, 2016

\begin{abstract}
This paper studies the welfare cost of inflation in a frictional monetary economy with endogenous consumer search. Equilibrium entails price dispersion, where sellers compete for buyers by posting prices. We identify three channels through which inflation affects welfare. The real balance channel is the source of welfare loss. Its interaction with the price posting channel generates a welfare cost larger than Lucas (2000). The search channel reduces the welfare cost by more than one half through general equilibrium effect. The aggregate effect of these three channels on welfare is non-monotonic. Additionally, the welfare cost of inflation fluctuations is negligible.
\end{abstract}

Keywords: Consumer Search, Inflation, Price Dispersion, Welfare

JEL: E31, E40, E50, D83

\footnotetext{
${ }^{*}$ I am thankful to Kenneth Burdett, Guido Menzio, and in particular Randall Wright for their invaluable input. Additional thanks go to Aleksander Berentsen, Richard Dutu, Allen Head, David Parsley, Adrian Peralta-Alva, Christopher Waller, and participants at the Search and Matching Workshop, AEA Annual Meeting, Midwest Macro Meetings, Econometric Society NASM, the seminars at the University of Pennsylvania and the Federal Reserve Bank of St. Louis. I am grateful to Guillaume Rocheteau, Richard Dutu, and David Parsley for sharing their data. All errors are mine.

${ }^{\dagger}$ Department of Economics, University of Hawaii Manoa, Honolulu, HI 96822. Email: lwang2@hawaii.edu.
} 


\section{Introduction}

There is a long tradition of thinking that the welfare cost of inflation has two major sources: the opportunity cost of holding money and price dispersion. In this paper, we revisit the classical question on welfare cost in a general equilibrium monetary model. We build on the New Monetarist framework of Lagos and Wright (2005), and integrate the analysis of endogenous price dispersion in a frictional goods market by Burdett and Judd (1983).

In this economy, buyers want to carry money despite a positive opportunity cost because they can use it as a medium of exchange in the bilateral trade market with frictions, in which other means of payment are infeasible due to anonymity and imperfect monitoring technology. Search frictions not only make money essential, but also give sellers monopolistic power to set prices. In the frictional market, buyers can only observe a subset of prices, and they need to pay a cost to acquire more price information. Therefore, when a seller serves buyers who do not search for lower prices, he is able to sell at prices higher than marginal cost, but then the seller can also post a lower price to attract other buyers who search. This trade-off generates endogenous price dispersion.

We identify three channels through which inflation affects welfare: real balance, price posting, and endogenous search. When inflation increases, holding money becomes more costly, and buyers reduce their real balances. As a result, consumption decreases, and so does welfare. This is the real balance channel. At the same time, buyers may want to search harder, in order to find a lower price and purchase more goods. Hence, an increase in search behavior increases consumption and welfare. The price posting channel does not respond to inflation directly, but is affected by the other two channels through general equilibrium effect. Sellers certainly post different prices if buyers bring less money to trade or search harder for low prices, and price changes affect consumption and welfare subsequently.

In order to understand the aggregate effect of inflation on welfare, as well as the effects through each individual channel, we calibrate the model to match the U.S. data on money demand and price dispersion, measure the welfare cost of inflation following Lucas (2000), and decompose the aggregate effect of inflation by shutting down each channel separately. Taking the economy with zero inflation as a benchmark, we find that the welfare cost of $10 \%$ annual inflation is worth $10.25 \%$ of consumption. However, if the price posting channel is shut down, welfare cost sharply decreases to $2.37 \%$. If the real balance channel is shut down, we actually find a small welfare gain of $0.16 \%$ at $10 \%$ inflation, due to increased search 
activities.

The decomposition exercise shows that, in our model, inflation affects welfare most directly through the real balance channel. While the effect through this channel alone is limited, its interaction with the price posting channel can generate a sizable welfare loss. When inflation increases, money holdings and consumption decrease. Since buyer's expenditure is not sensitive to price changes, sellers respond by posting even higher prices, which further reduces consumption and welfare. The search channel has two effects on welfare. First, if buyers search more, they are more likely to trade at lower prices, and hence consumption increases. Second, search activities increase competition among sellers, and drive down the average price level. Our quantitative exercise suggests that the second effect of the search channel on welfare is more important, and it reduces the welfare cost by $50 \%$.

The model predicts a non-monotonic effect of inflation on welfare. At a point very close to the Friedman rule, sellers still post prices above marginal cost. A small deviation from the Friedman rule can improve welfare by encouraging buyers to search harder for low prices and increasing competition among sellers. However, as the cost of holding money increases even more, real balances drop quickly, and inflation has a first-order effect on consumption. The joint negative effect of the real balance and the price posting channel outweighs the positive effect of the search channel, causing welfare cost to increase quickly. In the appendix, we apply an extension of the model to measure the welfare gain of smoothing monetary shocks, which is worth $0.15 \%$ of consumption in the benchmark economy. This result is larger than the previous literature, such as Lucas (1987) and Faig and Li (2009).

This paper fits into a long literature since Bailey (1956), which studies the welfare cost of inflation through the real balance channel. Among recent papers, Cooley and Hansen (1989) use a cash-in-advance constraint to introduce money into a real business cycle model and find the welfare cost of $10 \%$ inflation equals $0.52 \%$ of steady state consumption. Lucas (2000) surveys research on welfare cost in different frameworks, and estimates the welfare cost of $10 \%$ inflation to be less than $1 \%$ of real income. We find a larger welfare cost, but the effect of inflation through the real balance channel alone is in the same range as previous findings.

Following the New Monetarist literature, in our model, money is introduced via search frictions. Many papers in this literature, such as Lagos and Wright (2005), Craig and Rocheteau (2008a), and Rocheteau and Wright (2009), focus on the real balance channel and 
find a large welfare cost of inflation due to the holdup problem associated with bargaining. We consider price posting instead of bargaining, and present a new source of large welfare loss, even without the hold up problem. Due to the interactions of different channels, the welfare cost of inflation in our model is larger than the findings in those papers.

Several papers in this literature generate endogenous price dispersion in equilibrium. Head et al. (2012) also integrate the Lagos-Wright framework with Burdett and Judd (1983), but search intensity is exogenous. They show that the model can match the empirical evidence of price changes very well. In the same framework with indivisible goods, Liu et al. (2014) study money and credit as alternative means of payment. These two papers do not focus on welfare. Dutu et al. (2012) introduce second-price auction into the Lagos-Wright framework, and study the welfare cost (or gain) of price dispersion. Head and Kumar (2005) build on the large household framework in Shi (1997) to study the relationship between inflation and price dispersion. They also discuss welfare and present qualitative findings similar to those in our paper, but no quantitative results since they do not calibrate their model. In a cashless search model with price dispersion, Benabou (1988, 1992) and Diamond (1993) study the theoretical connection between inflation and efficiency. They ignore the real balance channel, which greatly affects welfare.

There are other frictions which can also generate price dispersion, such as Calvo pricing and menu costs in the New Keynesian literature. Burstein and Hellwig (2008) study a variety of New Keynesian models, and calculate a welfare cost, only under Calvo pricing, similar to the magnitude in Lagos and Wright (2005). Craig and Rocheteau (2008b) combine the Lagos-Wright framework with menu costs and find the optimal inflation rate is away from the Friedman rule. Aruoba and Schorfheide (2011) combine Lagos-Wright with Calvo pricing and find that the welfare distortions created by search frictions are of similar magnitude as the distortions created by the New Keynesian friction. All three papers include real balance and price posting channels. We add endogenous search, and focus on the welfare implication of the interaction of different channels.

The rest of the paper is organized as follows. Section 2 lays out the environment of the model, and we solve for stationary equilibrium in Section 3. Section 4 discusses calibration and data. Section 5 studies welfare and decomposes the effects through different channels. Section 6 concludes the paper. Stochastic money supply, additional technical details and proofs are in the appendix. 


\section{The Environment}

Time is discrete. Each period is divided into two subperiods. In the first subperiod, there is a decentralized market (hereafter DM) and goods are traded bilaterally. In the second subperiod, the market is centralized (hereafter CM) and there is Walrasian trade in the market. A continuum of buyers and sellers, each with measure one, live forever. Following Rocheteau and Wright (2005), assume both types produce and consume in the CM, but they act differently in the DM. Buyers want to consume but cannot produce, while sellers can produce but do not want to consume. All economic agents are assumed to be anonymous in the DM, and there is imperfect monitoring or record keeping technology. These assumptions, as well as the lack of double coincidence of wants, make a medium of exchange, which is called money, essential. ${ }^{1}$ Money is storable and perfectly divisible.

Money supply in period $t$ is denoted by $M_{t}$, and it grows according to $M_{t+1}=\gamma M_{t}$, where $M_{t+1}$ is the money supply in the next period $t+1$. New money is injected by lumpsum transfers, or withdrawn by lump-sum taxes if $\gamma<1$, at the beginning of the CM. For simplicity, we assume that transfer or tax goes equally to each buyer. ${ }^{2}$

In period $t$, the buyer's instantaneous utility function is

$$
U_{t}^{b}\left(x_{t}, h_{t}, q_{t}\right)=u\left(q_{t}\right)+v\left(x_{t}\right)-h_{t},
$$

where $q_{t}$ is the quantity of the DM goods consumed, $x_{t}$ is the quantity of the CM goods consumed, and $h_{t}$ is the quantity produced. The CM goods are produced one-for-one using labor. The lifetime utility of a buyer is $\sum_{t=0}^{\infty} \beta^{t} U_{t}^{b}$. Assume that $u(q)$ has the CRRA form with risk aversion coefficient $\sigma<1$ and $u(0)=0, u^{\prime}(q)>0, u^{\prime \prime}(q)<0$ for all $q$. Also assume $v^{\prime}(x)>0$ and $v^{\prime \prime}(x)<0$ for all $x$, and there exists $x^{*}>0$ such that $v^{\prime}\left(x^{*}\right)=1$. Similarly, the instantaneous utility of a seller is

$$
U_{t}^{s}\left(x_{t}, h_{t}, q_{t}\right)=-c q_{t}+v\left(x_{t}\right)-h_{t}
$$

where $q_{t}, x_{t}$, and $h_{t}$ have the same definitions as in the buyer's utility function. ${ }^{3}$ The lifetime

\footnotetext{
${ }^{1}$ For more discussions on the essentiality of money, please refer to a recent paper by Wallace (2011).

${ }^{2}$ Alternatively, we can assume that transfer or tax goes equally to each agent or each seller, and equilibrium results do not change.

${ }^{3}$ To simplify the analysis of the model, we assume that the seller's marginal cost of production is constant. The intuition behind does not change with more general forms of the cost function.
} 


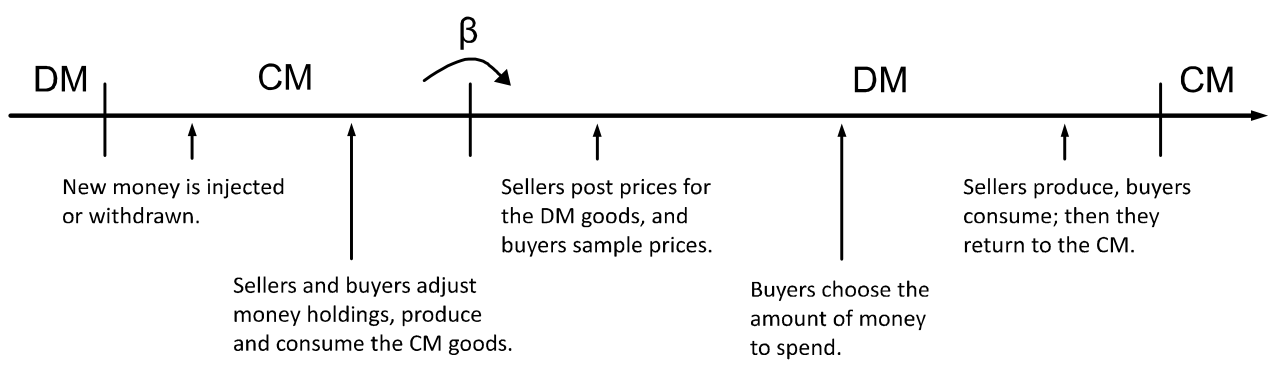

Figure 1: Timeline

utility of a seller is $\sum_{t=0}^{\infty} \beta^{t} U_{t}^{s}$. Let $u^{\prime}(q)=c$ hold for some $q^{*}>0$.

In the CM, the price of consumption good $x$ is normalized to one. The relative price of money in terms of $x$ is $\phi_{t}$ in period $t$ and the price of $x_{t}$ in terms of money is $1 / \phi_{t}$. Thus, the $\mathrm{CM}$ consumption good becomes the numeraire in the economy. $\beta$ is the discounting factor between today's CM and tomorrow's DM. This paper focuses on the case in which $\beta<\gamma$. Assume inflation is forecasted perfectly and the Fisher equation holds. Hence, the nominal interest rate $i$ is equal to $(\gamma-\beta) / \beta$, and $\beta<\gamma$ implies $i>0$.

\section{Search and Price Dispersion}

This paper studies a market structure in which sellers post prices and buyers know the price distribution but cannot observe all the prices. Burdett and Judd (1983) study a similar search protocol in a non-monetary model of indivisible goods. In this random search environment, buyers have the freedom to sample one or two prices, or equivalently, to visit one or two sellers with a search cost. They have knowledge about the price distribution but not about an individual price or an individual seller. Hence, a buyer cannot direct his search to the seller with the lowest price, and he has to visit a seller without knowing his price ex ante.

Figure 1 presents the timeline of the events. At the beginning of the CM in each period, new money is injected or withdrawn by the government. Then, both sellers and buyers adjust their monetary balances, produce, and consume the CM goods. After agents enter the DM in the next period, each seller posts prices for the DM goods, and he is committed to producing and selling any quantity of the goods at the price posted. Every buyer then chooses his search intensity by sampling one or two prices from the price distribution of the DM goods. ${ }^{4}$ After that, he still needs to decide how much money to spend in a trade.

\footnotetext{
${ }^{4}$ To ease the presentation, we limit the maximum number of prices that a buyer can sample to two. One
} 
Finally, each buyer trades with one seller. The seller produces, the buyer consumes, and then they return to the CM.

Sellers can randomize over a range of prices in the price posting stage. The induced price distribution in the DM in period $t$ is denoted as $F_{t}$ with support $\mathcal{Z}_{F_{t}}=\left[\underline{p}_{t}, \bar{p}_{t}\right]$. Based on the knowledge about $F_{t}$, buyers make their decisions on search intensity. After entering the DM, every buyer can observe one price for free and he can choose to pay cost $k$ to observe a second price. Buyers who choose not to sample a second price are type- 1 buyers, and the others are type- 2 buyers. The measure of type- 2 buyers is denoted by $\alpha_{t} \in[0,1]$, and $1-\alpha_{t}$ is the measure of type- 1 buyers.

The real balance that an agent carries in period $t$ is denoted as $z_{t}=m_{t} \phi_{t}$. Starting from this point, our analysis focuses on stationary monetary equilibrium where aggregate real variables stay constant. This implies that $\phi_{t} M_{t}=\phi_{t+1} M_{t+1}$ and $\phi_{t} / \phi_{t+1}=\gamma$. The rate of nominal price change, i.e., the inflation or deflation rate in the CM is equal to the money growth rate $\gamma$. In the DM, the rate of nominal price change is slightly more complicated due to the existence of price dispersion, and it may be greater or smaller than $\gamma$. From this point onwards we suppress the time subscript and use ${ }^{\wedge}$ to denote the variables of the next period. $W^{b}(z)$ and $V^{b}(z)$ are buyer's value functions in the CM and DM, respectively, and $W^{s}(z)$ and $V^{s}(z)$ are seller's value functions. We proceed first with the buyer's optimization problem.

\subsection{Buyer's Optimization Problem}

When a buyer enters the CM, he needs to decide whether he is going to observe one or two prices in the following DM. This choice affects the buyer's decision on production, consumption, and money holding in the CM. A type-1 buyer faces the following optimization problem in the recursive form.

$$
\begin{gathered}
W_{1}^{b}(z)=\max _{x_{1}, h_{1}, \hat{z}_{1}}\left\{v\left(x_{1}\right)-h_{1}+\beta V_{1}^{b}\left(\hat{z}_{1}\right)\right\} \\
\text { s.t. } h_{1}+z+T=x_{1}+\gamma \hat{z}_{1}
\end{gathered}
$$

$W_{1}^{b}(z)$ represents the value function in the CM and $V_{1}^{b}\left(\hat{z}_{1}\right)$ is the value of observing one price in the DM. The buyer produces the CM goods using labor as input, consumes, and adjusts

can extend the logic of Claim 1 in Burdett and Judd (1983, p. 962) and prove that in equilibrium with price dispersion, buyers endogenously choose not to sample more than two prices. 
his real balance of the next period $\hat{z}_{1} . T=(\gamma-1) \phi M$ is the transfer payment made by the government.

A type-2 buyer chooses to observe a second price with cost $k$ in the DM, and his optimization problem in the $\mathrm{CM}$ is characterized as

$$
\begin{gathered}
W_{2}^{b}(z)=\max _{x_{2}, h_{2}, \hat{z}_{2}}\left\{v\left(x_{2}\right)-h_{2}+\beta V_{2}^{b}\left(\hat{z}_{2}\right)\right\} \\
\text { s.t. } h_{2}+z+T=x_{2}+\gamma \hat{z}_{2}
\end{gathered}
$$

We define $V_{1}^{b}$ and $V_{2}^{b}$ explicitly later. Therefore, at the beginning of the CM, a buyer chooses the option with the higher value.

$$
W^{b}(z)=\max \left\{W_{1}^{b}(z), W_{2}^{b}(z)\right\}
$$

Let us look at $W_{1}^{b}(z)$ first. Substitute $h$ in the value function by the budget constraint, and (1) becomes

$$
W_{1}^{b}(z)=z+W_{1}^{b}(0)
$$

where $W_{1}^{b}(0)=\max _{x, \hat{z}_{1}}\left[v(x)-x+T-\gamma \hat{z}_{1}+\beta V_{1}^{b}\left(\hat{z}_{1}\right)\right]$. The buyer's optimal decision of $\hat{z}_{1}$ does not depend on his current money holding. Similarly, we have

$$
W_{2}^{b}(z)=z+W_{2}^{b}(0)
$$

and $W_{2}^{b}(0)=\max _{x, \hat{z}_{2}}\left[v(x)-x+T-\gamma \hat{z}_{2}+\beta V_{2}^{b}\left(\hat{z}_{2}\right)\right]$. Therefore,

$$
W^{b}(z)=z+\max \left\{W_{1}^{b}(0), W_{2}^{b}(0)\right\}=z+W^{b}(0)
$$

This convenient result is due to the assumption of quasi-linear utility function in the CM, which yields a degenerate distribution of buyers' money holdings in the DM.

Now we turn to the DM. The value function of a type- 1 buyer $V_{1}^{b}\left(z_{1}\right)$ is given by

$$
V_{1}^{b}\left(z_{1}\right)=\int_{\underline{p}}^{\bar{p}}\left\{u\left(\frac{d^{*}\left(p ; z_{1}\right)}{p}\right)+W^{b}\left[z_{1}-d^{*}\left(p ; z_{1}\right)\right]\right\} \mathrm{d} F(p)
$$

where $d^{*}\left(p ; z_{1}\right)$ represents the buyer's optimal expenditure on the DM goods, which depends on his money holding $z_{1}$ and transaction price $p$. After the buyer pays $d^{*}\left(p ; z_{1}\right)$ for the DM goods, he still carries a real balance of $z_{1}-d^{*}\left(p ; z_{1}\right)$, and $W^{b}\left[z_{1}-d^{*}\left(p ; z_{1}\right)\right]$ represents the 
continuation value of entering the next CM.

A type-2 buyer faces the following value function

$$
V_{2}^{b}\left(z_{2}\right)=\int_{\underline{p}}^{\bar{p}}\left\{u\left(\frac{d^{*}\left(p ; z_{2}\right)}{p}\right)+W^{b}\left[z_{2}-d^{*}\left(p ; z_{2}\right)\right]\right\} \mathrm{d}\left[1-(1-F(p))^{2}\right]-k
$$

where $d^{*}\left(p ; z_{2}\right)$ is defined similarly as $d^{*}\left(p ; z_{1}\right)$, and $1-(1-F(p))^{2}$ is the distribution of transaction price, i.e., the lower of two observed prices.

In order to solve for $d^{*}(p ; z)$, the buyer's optimal expenditure function, we apply the linearity of $W^{b}(z)$ from (5) and rewrite (6) and (7) as

$$
V_{1}^{b}\left(z_{1}\right)=\int_{\underline{p}}^{\bar{p}}\left\{u\left(\frac{d^{*}\left(p ; z_{1}\right)}{p}\right)-d^{*}\left(p ; z_{1}\right)\right\} \mathrm{d} F(p)+W^{b}\left(z_{1}\right)
$$

and

$$
V_{2}^{b}\left(z_{2}\right)=\int_{\underline{p}}^{\bar{p}}\left\{u\left(\frac{d^{*}\left(p ; z_{2}\right)}{p}\right)-d^{*}\left(p ; z_{2}\right)\right\} \mathrm{d}\left[1-(1-F(p))^{2}\right]-k+W^{b}\left(z_{2}\right) .
$$

It is obvious that $d^{*}(p ; z)$ is the solution to the following problem.

$$
\begin{gathered}
\max _{d \geq 0} u\left(\frac{d}{p}\right)-d \\
\text { s.t. } d \leq z
\end{gathered}
$$

A buyer chooses how much money to spend on the DM goods, and he cannot spend more than what he carries. The following Lemma explicitly characterizes $d^{*}(p ; z)$.

Lemma 1 The buyer's optimal spending rule is given by

$$
d^{*}(p ; z)= \begin{cases}z, & \text { if } p<\tilde{p} \\ d^{*}(p), & \text { otherwise }\end{cases}
$$

where $\tilde{p}$ and $d^{*}(p)$ satisfy $u^{\prime}(z / \tilde{p})=\tilde{p}$ and $u^{\prime}\left(d^{*}(p) / p\right)=p$, respectively, and $\partial \tilde{p} / \partial z<0$, $\partial d^{*}(p) / \partial p<0$.

The risk aversion coefficient $\sigma$ characterizes the buyer's price elasticity of demand. When $\sigma$ is less than one, the buyer's price elasticity of demand is greater than one, and the expenditure elasticity is less than one. Then, his expenditure on the DM goods $d^{*}(p ; z)$ decreases 


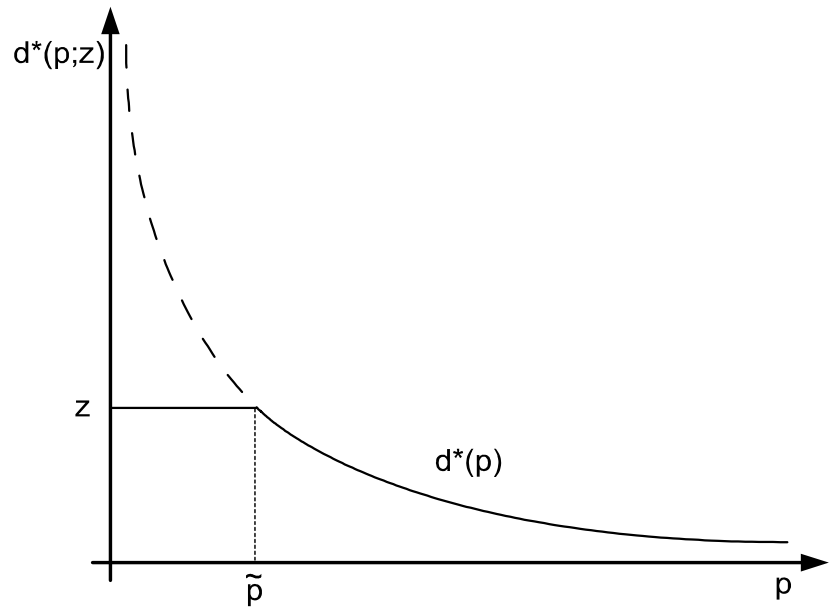

Figure 2: Buyer's Optimal Spending Rule in the DM

as he faces a higher price level. A buyer cannot spend more than his monetary constraint at low price levels even though he desires to do so. $\tilde{p}$ is the cutoff price level at which the buyer's monetary constraint starts to relax, and he spends less than the total money holding when the price is higher than $\tilde{p}$. This situation is illustrated in Figure 2.

We substitute (8) and (9) into (3) and (4). The buyer's Bellman's equations in the CM become

$$
\begin{aligned}
W_{1}^{b}(z)= & z+\max _{x, \hat{z}_{1}}\left\{v(x)-x+T-\gamma \hat{z}_{1}+\beta W^{b}\left(\hat{z}_{1}\right)\right. \\
& \left.+\beta \int_{\underline{p}}^{\bar{p}}\left[u\left(\frac{d^{*}\left(p ; \hat{z}_{1}\right)}{p}\right)-d^{*}\left(p ; \hat{z}_{1}\right)\right] \mathrm{d} F(p)\right\}
\end{aligned}
$$

and

$$
\begin{aligned}
W_{2}^{b}(z)= & z+\max _{x, \hat{z}_{2}}\left\{v(x)-x+T-\gamma \hat{z}_{2}+\beta W^{b}\left(\hat{z}_{2}\right)-\beta k\right. \\
& \left.+\beta \int_{\underline{p}}^{\bar{p}}\left[u\left(\frac{d^{*}\left(p ; \hat{z}_{2}\right)}{p}\right)-d^{*}\left(p ; \hat{z}_{2}\right)\right] \mathrm{d}\left[1-(1-F(p))^{2}\right]\right\}
\end{aligned}
$$

The optimal decision of $x$ satisfies $v^{\prime}\left(x^{*}\right)=1$, and it does not depend on $\hat{z}_{1}$ or $\hat{z}_{2}$.

According to Lemma $(1), d^{*}(p ; z)$ has different expressions depending on the relationship between $p$ and $\tilde{p}$. Therefore, in order to characterize the buyer's optimal decision on $\hat{z}_{1}$ and $\hat{z}_{2}$, we first need to establish the following result characterizing the relationship of $\tilde{p}$ and $\mathcal{Z}_{F}$.

Lemma 2 In the optimization problem in (11) and (12), both type-1 and type-2 buyers 
always choose real balances $\hat{z}_{1}$ and $\hat{z}_{2}$ such that $\tilde{p}_{1}>\underline{p}$ and $\tilde{p}_{2}>\underline{p}$.

The intuition of Lemma 2 is straightforward. Consider type- 1 buyers as an example. If the cutoff price $\tilde{p}_{1}$ is smaller than the lower limit of price distribution, the buyer's real balance does not affect the surplus from trade in the DM since $d^{*}\left(p ; z_{1}\right)$ equals $d^{*}(p)$. The marginal benefit of bringing more money to the DM is zero, while the marginal cost is still positive. Thus, a buyer wants to reduce his real balance until there is a positive marginal gain related to the action of carrying money, which only happens when $\tilde{p}_{1}$ exceeds $\underline{p}$. This intuition is true for both type-1 and type- 2 buyers.

We proceed to characterize the optimal decisions of buyers. Taking $F(p)$ as given, a type- 1 buyer chooses $\hat{z}_{1}$ to solve the maximization problem in (11). We can rewrite the buyer's value function in the CM as the following

$$
\begin{aligned}
W_{1}^{b}(z) \simeq & \max _{\hat{z}_{1}}\left\{-\gamma \hat{z}_{1}+\beta \int_{\underline{p}}^{\tilde{p}_{1}}\left[u\left(\frac{\hat{z}_{1}}{p}\right)-\hat{z}_{1}\right] \mathrm{d} F(p)\right. \\
& \left.+\beta \int_{\tilde{p}_{1}}^{\bar{p}}\left[u\left(\frac{d^{*}(p)}{p}\right)-d^{*}(p)\right] \mathrm{d} F(p)+\beta W^{b}\left(\hat{z}_{1}\right)\right\},
\end{aligned}
$$

and the terms unrelated to $\hat{z}_{1}$ are omitted. So the buyer's optimal real balance $\hat{z}_{1}^{*}$ satisfies

$$
\int_{\underline{p}}^{\tilde{p}_{1}}\left[u^{\prime}\left(\frac{\hat{z}_{1}^{*}}{p}\right) \frac{1}{p}-1\right] \mathrm{d} F(p)=i .
$$

The buyer's marginal gain of holding money, which is the left hand side of (14), decreases as $\hat{z}_{1}^{*}$ increases. Holding everything else constant, there is less marginal gain as a buyer holds more money. From a partial equilibrium point of view, as the money growth rate increases, the nominal interest rate rises, the marginal cost of holding money gets bigger, and the buyer decides to carry a smaller real balance.

The price distribution $F(p)$ also affects the buyer's money holding in the following way. If $\tilde{F}(p)$ first-order stochastically dominates $F(p)$, a buyer carries less money with $\tilde{F}(p)$. Because he faces a smaller probability of getting a low price, implying a smaller probability of becoming cash-constrained and a smaller marginal gain of holding extra money. Therefore, the marginal benefit of carrying money is smaller than the marginal cost, and the buyer wants to reduce his money holding.

Next, a type- 2 buyer chooses $\hat{z}_{2}$ to solve the maximization problem in (12) and we can 
rewrite the value function in a similar way as

$$
\begin{aligned}
W_{2}^{b}(z) \simeq & \max _{\hat{z}_{2}}\left\{-\gamma \hat{z}_{2}+\beta \int_{\underline{p}}^{\tilde{p}_{2}}\left[u\left(\frac{\hat{z}_{2}}{p}\right)-\hat{z}_{2}\right] \mathrm{d}\left[1-(1-F(p))^{2}\right]\right. \\
& \left.+\beta \int_{\tilde{p}_{2}}^{\bar{p}}\left[u\left(\frac{d^{*}(p)}{p}\right)-d^{*}(p)\right] \mathrm{d}\left[1-(1-F(p))^{2}\right]+\beta W^{b}\left(\hat{z}_{2}\right)\right\} .
\end{aligned}
$$

Then, the buyer's optimal real balance $\hat{z}_{2}^{*}$ satisfies the following FOC

$$
\int_{\underline{p}}^{\tilde{p}_{2}}\left[u^{\prime}\left(\frac{\hat{z}_{2}^{*}}{p}\right) \frac{1}{p}-1\right] \mathrm{d}\left[1-(1-F(p))^{2}\right]=i
$$

and the same intuition as $\hat{z}_{1}^{*}$ applies. The following lemma shows that type-2 buyers always carry more money than type- 1 buyers, since type- 2 buyers face lower prices than type- 1 buyers and their marginal benefit of carrying money is higher.

Lemma 3 Given the price distribution $F(p)$ in the DM, a type-2 buyer carries more money than a type-1 buyer, i.e. $\hat{z}_{1}^{*}<\hat{z}_{2}^{*}$.

\subsection{Seller's Optimization Problem}

In the CM, the seller's value function is

$$
\begin{gathered}
W^{s}(z)=\max _{x, h, \hat{z}}\left[v(x)-h+\beta V^{s}(\hat{z})\right] \\
\text { s.t. } h+z=x+\gamma \hat{z}
\end{gathered}
$$

where $\hat{z}$ is the seller's real money balance of the next period. In the CM, a seller produces and consumes the CM goods and chooses the amount of money to bring to the next DM. Similar to the buyer's problem, the seller's optimal quantity of the CM consumption $x^{*}$ satisfies $v^{\prime}\left(x^{*}\right)=1$. We also have $W^{s}(z)=z+W^{s}(0)$, and the seller's optimal real balance $\hat{z}^{*}$ does not depend on $z$.

We then turn to the seller's value function in the DM, which is

$$
V^{s}(\hat{z})=\max _{p \geq c} \pi(p)+W^{s}(\hat{z})
$$

where $\pi(p)$ is the seller's profit function and does not depend on his money holding. We

substitute (18) into (17), and an immediate result for the seller is $\hat{z}^{*}=0$ since $\gamma>\beta$. The 
seller does not bring any money to the DM because he does not want to consume, and the profit is not affected by his real balance.

In the DM, a seller takes the buyer's optimal real balances, the measure of different types of buyers, and the price distribution in the market as given. He chooses a price to maximize the following profit function

$$
\pi(p)=(1-\alpha)\left(d^{*}\left(p ; z_{1}\right)-c \frac{d^{*}\left(p ; z_{1}\right)}{p}\right)+2 \alpha(1-F(p))\left(d^{*}\left(p ; z_{2}\right)-c \frac{d^{*}\left(p ; z_{2}\right)}{p}\right)
$$

where $z_{1}$ and $z_{2}$ represent the buyer's real balance and $\alpha$ is the measure of type- 2 buyers in the same period of the seller's price posting problem, and $d^{*}$ is the buyer's optimal expenditure on the DM goods. With probability $1-\alpha$, the seller is the only one that a buyer visits, and with probability $\alpha$, he is competing with another seller for the same buyer. In that situation, the seller can have a successful trade only if his price is lower than his competitor's price, which happens with probability $1-F(p)$. Finally, $d^{*}\left(p ; z_{i}\right)-c d^{*}\left(p ; z_{i}\right) / p, i=1$, 2 , denotes the seller's surplus from trade.

We proceed to characterize the upper and lower limit of $F(p)$. Facing the price distribution in the DM, the highest price posted by a seller must be equal to or higher than $\bar{p}$, in which case the seller expects to trade with buyers who only visit him, i.e., type-1 buyers only. This seller does not face any competition from other sellers, and his profit function becomes

$$
\pi\left(\bar{p}^{\prime}\right)=(1-\alpha)\left(d^{*}\left(\bar{p}^{\prime} ; z_{1}\right)-c \frac{d^{*}\left(\bar{p}^{\prime} ; z_{1}\right)}{\bar{p}^{\prime}}\right)
$$

where $\bar{p}^{\prime}$ is the highest price that the seller chooses to post given $F(p)$ and its support $\mathcal{Z}_{F}$. Notice that this is the same problem faced by every seller, and the optimal choice of $\bar{p}^{\prime}$ does not depend on distribution $F$. Therefore, the upper limit of $F(p), \bar{p}$ is determined by the following lemma.

Lemma 4 Given the optimal money holding of type-1 buyers $z_{1}$ and the buyer's optimal expenditure rule $d^{*}\left(p ; z_{1}\right)$, the upper limit of the price distribution $F(p)$ is given by $\bar{p}=$ $\max \left\{\tilde{p}_{1}, \check{p}\right\}$, where $\check{p}$ satisfies $d^{*}(\check{p}) u^{\prime \prime}\left(d^{*}(\check{p}) / \check{p}\right) / \check{p}+\check{p}-c=0$ and $\tilde{p}_{1}$ is defined in Lemma 1 by $u^{\prime}\left(z_{1} / \tilde{p}_{1}\right)=\tilde{p}_{1}$.

Figure 3 shows the seller's profit as a function of price posted, taking into account the buyer's optimal expenditure in the DM. Notice that the seller's actual profit function is the lower envelope of two separate curves. When the buyer's price elasticity of demand is greater 


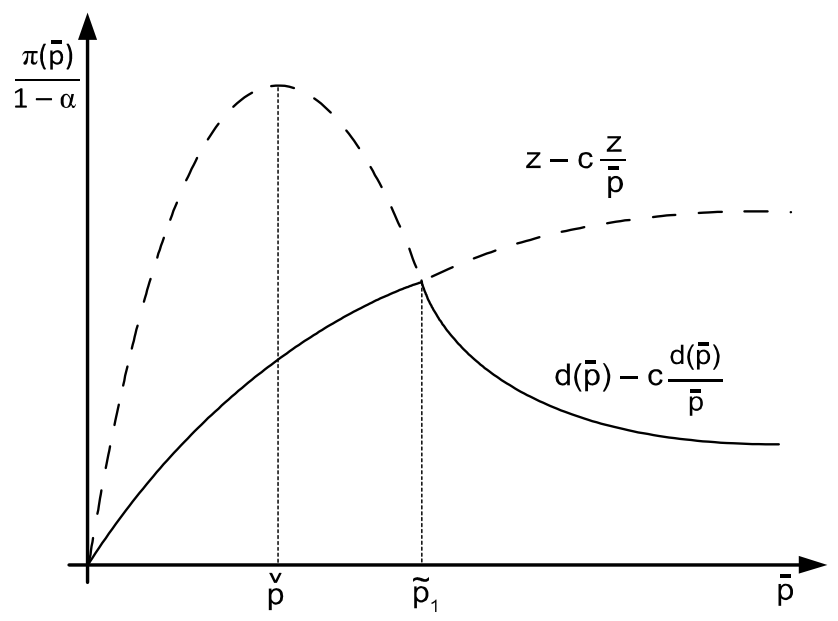

Figure 3: Seller's Profit per Trade in the DM

than one, his spending on the DM good decreases with price. Then, without the monetary constraint, the seller chooses to post $\check{p}$ to maximize his profit $d^{*}(p)-c d^{*}(p) / p$. On the other hand, the buyer cannot spend more than the amount of money he carries into the DM, and the monetary constraint is binding for prices lower than $\tilde{p}_{1}$. For higher prices, the buyer wants to spend less, and the constraint is not binding at all.

When the nominal interest rate is high, it is relatively more costly to hold money for buyers, and it is more likely to have $\check{p}<\tilde{p}_{1}$. This case is illustrated in Figure 3 . When the interest rate is low and carrying money is less costly, it is possible to have $\check{p}>\tilde{p}_{1}$, in which case the seller can earn the highest possible profit at $\check{p}$.

The next lemma characterizes the price distribution in the DM.

Lemma 5 Given the buyer's optimal choices on real balance $z_{1}$ and $z_{2}$ and the measure of type-2 buyers $\alpha$, the price posting equilibrium distribution $F(p)$ in the DM is uniquely characterized as

(i) if $\alpha=0, F(p)$ is concentrated at $\bar{p}$.

(ii) if $\alpha=1, F(p)$ is concentrated at $c$.

(iii) if $\alpha \in(0,1), F(p)$ is nondegenerate and $\mathcal{Z}_{F}=[\underline{p}, \bar{p}]$ is connected, and for any $p \in \mathcal{Z}_{F}$,

$$
F(p)=1-\frac{1-\alpha}{2 \alpha}\left[\frac{d^{*}\left(\bar{p} ; z_{1}\right)(\bar{p}-c) p}{d^{*}\left(p ; z_{2}\right)(p-c) \bar{p}}-\frac{d^{*}\left(p ; z_{1}\right)}{d^{*}\left(p ; z_{2}\right)}\right]
$$


where $\bar{p}$ is given in Lemma 4 and $\underline{p}$ satisfies

$$
\frac{(1-\alpha) d^{*}\left(\underline{p} ; z_{1}\right)+2 \alpha d^{*}\left(\underline{p} ; z_{2}\right)}{(1-\alpha) d^{*}\left(\bar{p} ; z_{1}\right)}=\frac{(\bar{p}-c) \underline{p}}{(\underline{p}-c) \bar{p}} .
$$

If every buyer samples just one price, i.e. $\alpha=0$, each seller behaves like a monopolist, and they all post a price as high as possible in order to extract all the surplus from trade. If every buyer samples two prices, each seller is facing competition from another seller. The seller's price posting game becomes a Bertrand competition, and the competitive price, which is equal to the marginal cost, is posted in equilibrium.

If some of the buyers choose to sample one price while others sample two, a certain degree of competition is introduced between sellers. When a seller decides what price to post, he can post a high price, gets more profit per trade, but mostly serves only type-1 buyers. Alternatively, he can post a low price, gets less profit per trade, but serves many more type- 2 buyers. The seller faces a trade-off between trade volume and profit per trade. Hence, he is indifferent within an interval of prices, each generating the same expected profit. This is the cause of the nondegenerate price distribution when $\alpha \in(0,1)$. If we focus on a symmetric equilibrium in which all sellers choose the same strategy, every seller posts price $p$ with probability $f(p)$, and $f(p)=d F(p) / d p$.

If more buyers search harder by sampling two prices, $F(p)$ increases. The upper limit of the price distribution does not change, since it is determined by type-1 buyer's money holding alone, while the lower limit decreases due to intensified competition. Price dispersion, measured as the length of the support of $F(p)$, increases. Increased search behavior intensifies competition among sellers; thus, it is more likely for a buyer to get a relatively low price, and, in general, the average price decreases.

If the nominal interest rate increases and type- 1 buyers bring less money to the DM, $\bar{p}$ increases, but the effect on $F(p)$ depends on $\sigma$. When $\sigma$ is less than one and the buyer's demand elasticity is greater than one, sellers respond by increasing the highest price in the market. Then, by the seller's equal profit condition, the overall price level in the DM rises and $F(p)$ decreases. 


\subsection{Equilibrium}

Before defining equilibrium, we close the model by characterizing the buyer's entry decision. When a buyer enters the CM, he first needs to choose to be a type- 1 or type- 2 buyer, and then makes other optimal choices based on his initial decision on type. The economy can only reach an equilibrium if the marginal buyer is indifferent between being type- 1 or type2. Given an existing composition of the buyer's population, there is not a single buyer who wants to change his type. That is, we need to have $W_{1}^{b}(z)=W_{2}^{b}(z)$ in order to make $\alpha^{*} \in(0,1)$. Set (11) equal to (12) and define

$$
\begin{aligned}
\Phi(\alpha)= & \int_{\underline{p}}^{\bar{p}}\left[u\left(\frac{d^{*}\left(p ; z_{2}^{*}\right)}{p}\right)-d^{*}\left(p ; z_{2}^{*}\right)\right] \mathrm{d}\left[1-(1-F(p))^{2}\right] \\
& -\int_{\underline{p}}^{\bar{p}}\left[u\left(\frac{d^{*}\left(p ; z_{1}^{*}\right)}{p}\right)-d^{*}\left(p ; z_{1}^{*}\right)\right] \mathrm{d} F(p)-i\left(z_{2}^{*}-z_{1}^{*}\right)
\end{aligned}
$$

to be the gain of observing two prices instead of one. Then, $W_{1}^{b}(z)=W_{2}^{b}(z)$ is equivalent to $\Phi(\alpha)=k$.

A buyer can get a better deal by sampling one more price, but he also needs to pay the extra opportunity cost of carrying more money. In order to have an interior solution of $\alpha$, the above gain needs to be equal to the cost $k$. Intuitively, if the gain from sampling the second price is less than $k$, we have $\alpha^{*}=0$ and all buyers are type-1. If the gain is larger than the cost, $\alpha^{*}$ equals 1 and all buyers choose to be type-2. Notice that even though $\alpha$ does not enter (21) directly, it appears in the price distribution $F(p)$ in equilibrium.

Definition 1 A stationary monetary equilibrium (SME) is a profile $\left\{F^{*}, z_{1}^{*}, z_{2}^{*}, x^{*}, h^{*}, d^{*}, \alpha^{*}\right\}$ satisfying the following conditions:

1. Given $d^{*}, z_{1}^{*}, z_{2}^{*}$, and $\alpha^{*}$, sellers post profit-maximizing prices in the DM and the resulting price distribution $F^{*}$ is determined by Lemma 5;

2. Given $F^{*}, d^{*}$, and $\alpha^{*}, z_{1}^{*}, z_{2}^{*}, x^{*}$, and $h^{*}$ solve the buyer's problem in the CM;

3. Given $F^{*}, z_{1}^{*}$, and $z_{2}^{*}$, the buyer's optimal spending rule in the $D M, d^{*}$, satisfies Lemma 1 ;

4. Given $F^{*}, d^{*}, z_{1}^{*}$, and $z_{2}^{*}$, buyers optimize the number of price samplings in the DM and $\alpha^{*}$ is the resulting measure of type-2 buyers.

In equilibrium, money bears value and circulates because buyers can use it as means of payment in the DM and sellers may use it in exchange for consumption goods in the CM. 
Equilibrium is symmetric in the sense that all ex-ante homogeneous sellers post the same price distribution. In general, two kinds of equilibrium may potentially exist: one with a degenerate price distribution in the $\mathrm{DM}$ and one with a nondegenerate price distribution. Proposition 1 shows that the first kind of equilibrium does not exist.

Proposition 1 If $\gamma>\beta$, there exists no SME with $\alpha^{*}=0$ or $\alpha^{*}=1$.

If all the buyers choose to be type- 2 and $\alpha=1$, the equilibrium price distribution becomes degenerate and concentrated at the marginal cost. Then, any type-2 buyer would want to deviate and switch to type-1, since the marginal gain from observing one more price is zero but he has to pay a non-zero cost. The equilibrium then collapses.

If all the buyers sample just one price and $\alpha=0$, the equilibrium price distribution again becomes degenerate and concentrated at the highest possible price, i.e. the seller's monopoly price. When posting this price, sellers do not take into account the buyer's opportunity cost of holding money, because it is a sunk cost in the DM. Then, when the buyer chooses the optimal real balance in the $\mathrm{CM}$, he finds that the marginal cost of carrying money to the DM is positive while the marginal gain is zero, since all the surplus from DM trade is exploited by the seller. Therefore, the buyer chooses $z_{1}^{*}=0$ and this is no longer a monetary equilibrium.

In the next proposition, we establish the existence of a stationary monetary equilibrium with a nondegenerate price distribution

Proposition 2 For $\gamma>\beta$, there exists $\bar{k}>0$, and for $k<\bar{k}$, SME with nondegenerate price distribution exists.

This proposition is proved in the appendix, and here we discuss the intuition behind the argument. First, based on (19) in Lemma 5, we show that the price distribution in the DM is decreasing, in the sense of first-order stochastic dominance, with respect to the real balance that type- 1 and type- 2 buyers are expected to hold, $z_{1}$ and $z_{2}$. If buyers of either type carry a larger $z$, the monetary constraint in the buyer's optimal expenditure problem (10) is relaxed. This implies that buyers now have more money to spend when they meet sellers with low prices, and hence low-price sellers get more profit compared to high-price sellers. Therefore, sellers choose to post low prices with a higher probability and $F$ shifts down. This leads to more sellers at low prices in the DM, and compared to high-price sellers, the expected number of type-2 buyers at each low-price seller decreases. While profit per trade is higher for low-price sellers, their trade volume is lower. 
Second, we show that the buyers' real balances, $z_{1}$ and $z_{2}$, decrease with the price distribution $F$. When buyers face a lower price distribution in the DM, in the sense of first-order stochastic dominance, they are more likely to meet sellers with low prices, and the probability of being cash-constrained is higher, as depicted in Figure 2. Hence, the buyer's marginal benefit of carrying one more dollar in (14) and (16) increases, and buyers simply choose to carry more money.

The above two steps establish a monotone relationship between the buyer's money holding decision and the seller's price posting decision. Furthermore, no one wants to carry additional money when it can no longer relax the buyer's cash constraint in the DM. Thus, there exists an upper bound on the buyer's choice of real balance. Then, from the fixed point theorem in Tarski (1955), we can prove that for a given measure of type-2 buyers, $\alpha \in(0,1)$, there exists $z_{1}^{*}$ and $z_{2}^{*}$ for type-1 and type-2 buyers, and hence $F^{*}$ for sellers.

Finally, we show that the type-2 buyer's surplus from the DM trade is larger than the type-1 buyer's. Intuitively, type-2 buyers carry more money and face lower transaction prices. The benefit they get outweighs the additional inflation tax that they need to pay on $z_{2}^{*}-z_{1}^{*}$. After type-2 buyers pay $k$, the payoffs of both types are the same and no one wants to deviate. Therefore, there exists $\alpha^{*} \in(0,1)$ such that $\Phi\left(\alpha^{*}\right)-k=0$, which in turn determines $z_{1}^{*}, z_{2}^{*}$, and $F^{*}$ in equilibrium. For equilibrium to exist at a given $i$, we need to guarantee that the search cost $k$ does not exceed the maximum benefit that type- 2 buyers get by sampling one more price, and hence $\bar{k}$ exists. Although we cannot formally prove the uniqueness of equilibrium, we can make a similar argument as in Wright (2010). When there are more than one $\alpha$ that satisfies $\Phi(\alpha)-k=0$, the biggest $\alpha$ is the one that yields the highest surplus for type- 2 buyers, and hence it is the equilibrium measure of type- 2 buyers.

\subsection{Discussion}

In this model, inflation affects consumption and welfare through three channels. First, inflation directly affects the opportunity cost of holding money in (14) and (16), and changes the real balance $z_{1}$ and $z_{2}$, which then affect consumption and welfare. This is the real balance channel. Second, inflation has a direct impact on the measure of type-2 buyers by changing the value of $i\left(z_{2}^{*}-z_{1}^{*}\right)$ in $(21)$, and a change in $\alpha$ then affects consumption and welfare. This is the search channel. The third is the price posting channel. Although $i$ does not enter (19) directly, it affects $F$ through changing $z_{1}, z_{2}$, and $\alpha$. 
Each channel affects welfare both directly and indirectly. As the cost of holding money increases, a decrease in $z_{1}$ and $z_{2}$ lowers the consumption of buyers and hence reduces welfare. This is the direct impact of the real balance channel. The real balance, $z$ also affects $F$ and $\alpha$ through the general equilibrium effect. A decrease in the real balance causes $F$ to increase, in the sense of first-order stochastic dominance, and hence the average price in the DM increases, which further reduces consumption. A decrease in $z_{1}$ and $z_{2}$ also lowers the gain of sampling two prices in $\Phi$ and causes $\alpha$ to drop, which has a negative effect on welfare.

Along the price posting channel, higher prices in the DM directly lower consumption and welfare. If $F$ is higher, buyers are less likely to face low prices and become cash-constrained. Hence, the marginal gain of carrying money is smaller, $z$ decreases, and so does consumption. On the other hand, higher prices increase the gain of search in (21) and cause $\alpha$ to go up, which positively affects welfare by decreasing the average transaction price. Hence, the general equilibrium effect of $F$ on welfare is ambiguous.

Regarding the search channel, lower $z_{1}$ and $z_{2}$ and higher $F$ have opposite effects on $\alpha$. Depending on which effect is larger, $\alpha$ may either increase or decrease with $i$ in equilibrium. An increase (decrease) in $\alpha$ implies more (fewer) buyers are trading at low prices in the DM, which directly leads to higher (lower) total consumption and welfare. While $\alpha$ does not enter (14) and (16) directly, it affects $z_{1}$ and $z_{2}$ by changing the price distribution $F$. When more (fewer) buyers sample two prices, there is more (less) competition between sellers, and $F$ decreases (increases), in the sense of first-order stochastic dominance. Then, the average

price decreases (increases) and consumption will rise (fall). Therefore, the overall effect of the search channel on welfare is ambiguous, depending on how $\alpha$ changes with $i$ in equilibrium.

In summary, inflation has the most direct impact on welfare through the real balance channel. Then, the initial effect will spread through the price posting and search channels. Due to the general equilibrium feedback, the total impact of inflation on welfare is amplified by the interaction of these three channels. In order to identify the importance of each individual channel and their interaction, we need to solve the model numerically and decompose the welfare cost.

\section{Calibration}

We want to match the statistics derived from an empirical money demand function and the magnitude of price dispersion in the micro data. As in Lucas (2000), the money demand 
function is defined as $L(i)=M / P Y$, representing real balance as a function of nominal interest rate. Real balance $M / P$ is proportional to the total real output $Y$ with a factor of proportionality $L(i)$, which depends on the opportunity cost of holding money. We assume the CM utility function to be $v(x)=A \log x$, following the literature on the welfare cost of inflation since Cooley and Hansen (1989). The per capita real output in the CM is then given by $x^{*}=A$. The utility of DM goods has the CRRA form $u(q)=q^{1-\sigma} /(1-\sigma)$, and the cost function is linear. We assume the marginal cost of production to be one, so that the cost of labor is the same in both markets. Given the real output in the DM

$$
(1-\alpha) \int_{\underline{p}}^{\bar{p}} \frac{d\left(p ; z_{1}\right)}{p} \mathrm{~d} F(p)+\alpha \int_{\underline{p}}^{\bar{p}} \frac{d\left(p ; z_{2}\right)}{p} \mathrm{~d}\left[1-(1-F(p))^{2}\right],
$$

we can explicitly express the money demand function in the model as

$$
L_{i}=\frac{(1-\alpha) z_{1}+\alpha z_{2}}{2 A+(1-\alpha) \int_{\underline{p}}^{\bar{p}} \frac{d\left(p ; z_{1}\right)}{p} \mathrm{~d} F(p)+\alpha \int_{\underline{p}}^{\bar{p}} \frac{d\left(p ; z_{2}\right)}{p} \mathrm{~d}\left[1-(1-F(p))^{2}\right]} .
$$

We target the average money demand $\mathbb{E} L_{i}$ and its elasticity $\eta_{i}$ in the data.

Another key statistic is the magnitude of price dispersion, computed using posted prices. It is important because, given different values of search cost $k$, the price posting equilibrium in the DM varies from marginal-cost pricing to monopoly, with different levels of price dispersion. Hence, price dispersion contains information about $k$. We measure price dispersion as the standard deviation of a standardized price, $p_{s}=p / p_{\text {ave }}$, where $p$ follows $F(p)$ and $p_{\text {ave }}$ is the quantity-weighted average of posted prices, defined in (22).

$$
p_{\text {ave }}=\frac{\alpha \int_{\underline{p}}^{\bar{p}} d\left(p, z_{2}\right) \mathrm{d}\left[1-(1-F(p))^{2}\right]+(1-\alpha) \int_{\underline{p}}^{\bar{p}} d\left(p, z_{1}\right) \mathrm{d} F(p)}{\alpha \int_{\underline{p}}^{\bar{p}} \frac{d\left(p, z_{2}\right)}{p} \mathrm{~d}\left[1-(1-F(p))^{2}\right]+(1-\alpha) \int_{\underline{p}}^{\bar{p}} \frac{d\left(p, z_{1}\right)}{p} \mathrm{~d} F(p)}
$$

In the following, we jointly choose $A, \sigma$, and $k$ to match the three targets: average money demand $\mathbb{E}_{i}$, the elasticity of money demand $\eta_{i}$, and price dispersion $\epsilon_{p_{s}}$. Each one of these parameters influences one target most directly. The preference parameter $A$ determines the output produced in the CM, and hence it directly affects the money demand through total output. The CRRA coefficient $\sigma$ determines the price elasticity of demand for the DM goods, and then it directly affects the elasticity of money demand with respect to $i$. Finally, the search cost $k$ determines the level of competition in the DM through the measure of type-2 buyers, and thus directly affects the degree of price dispersion. 
In order to numerically solve the model, we first take the measure of type-2 buyers $\alpha$ and real balance $z_{1}$ and $z_{2}$ as given, and use Lemma 5 to compute the uniquely determined price distribution $F$. Then, we substitute $F$ back into (14) and (16) to solve for $z_{1}$ and $z_{2}$. Finally, we substitute $z_{1}, z_{2}$ and $F$, which are all implicit functions of $\alpha$, into (21) and search for $\alpha \in(0,1)$ that solves $\Phi(\alpha)=k$. If there is more than one solution, we choose the biggest $\alpha$, according to Wright (2010).

\subsection{Data}

There are various sources of U.S. data on money demand in the literature. Lucas (2000) uses annual series of the ratio of M1 to nominal GDP and a short-term nominal interest rate, for the period 1900-1994. Lagos and Wright (2005) and Craig and Rocheteau (2008a) use the same data over a longer period of time, from 1900 to 2000. Cynamon et al. (2006) adjust the M1 data for swept funds in different sweep programs and provide shorter monthly series for the period 1959-2012. Lucas and Nicolini (2015) adjust M1 for money-market deposit accounts and provide an annual series for 1915-2012. To ease the comparison of our findings with earlier results, we set the time period of the model to be one year, and use the annual series from 1900-2000, including the not-seasonally-adjusted nominal GDP and M1, ${ }^{5}$ and short-term (6 month) commercial paper rate as the nominal interest rate. ${ }^{6}$ In these data, the average money demand is $\mathbb{E} L_{i}=0.2697$ at an average annual nominal interest rate of $4.65 \%$, and the elasticity is $\eta_{i}=-0.3564$.

Regarding the degree of price dispersion, there are various sources. Debelle and Lamont (1997) study two balanced panels of CPI data from the BLS, for the period 1954-1986 and 1977-1986. Most of the goods and services covered in their data are from the retail sector. They report an average price dispersion of 0.035. Parsley (1996) studies a quarterly panel of survey data from the Cost of Living Index 1975-1992, published by the American Chamber of Commerce Researchers Association, and reports an average price dispersion of 0.0923. In a recent paper, Kaplan and Menzio (2015) use data from the Kilts-Nielsen Consumer Panel

\footnotetext{
${ }^{5}$ Nominal GDP is taken from the Historical Statistics of the United States, Colonial Times to Present (1970) and the GDPA series from the Citibase database. Money supply is M1, as of December of each year, and is not seasonally adjusted. It is from the Historical Statistics of the United States (1970), Friedman and Schwartz (1963), and the FRED II database of the Federal Reserve Bank of St. Louis.

${ }^{6}$ From 1900 to 1997, the short-term commercial paper rate is taken from Friedman and Schwartz (1982), Economic Report of the President (1996), and Economic Report of the President (2003). From 1998 to 2000 it is the short-term 90-day AA credit rate from the Federal Reserve Board.
} 
(KNCP) data set 2004-2009 to study the shape and structure of price distribution. They find that $90 \%$ of all goods feature more than $10 \%$ price dispersion. They report the average price dispersion across all goods is 19\%-36\%, depending on how narrow the definition of the goods is. Search frictions can explain about $35 \%$ of the observed dispersion. We choose the target for price dispersion to be 0.035, which is at the low end of the range and implies a small cost of search. Later, we will vary the value of search cost and discuss the effect of $k$ on welfare results.

\subsection{Basic Findings}

Generally, we are able to pick parameters $A, \sigma$, and $k$ to hit the three targets exactly. Table 1 presents the calibration results. The calibrated value of $A$ implies that, at the average nominal interest rate, the DM market share is less than $20 \%$ of the total output. The value of $\sigma$ is small, implying a relatively large elasticity of demand for the DM goods. The baseline calibration also yields a small search cost, which is worth less than $0.1 \%$ of the buyer's expected utility in the DM, and it implies about $15 \%$ of the agents in the economy sample two prices. We can calculate the markup in the DM as $\mu_{D M}=\int_{\underline{p}}^{\bar{p}}(p / c) \mathrm{d} F(p)$, and the calibrated parameters imply $\mu_{D M}=1.37$, which is close to Bethune et al. (2016).

\begin{tabular}{|c|c|c|c|}
\hline$A$ & CM preference & average money demand 0.2697 & 0.7005 \\
\hline$\sigma$ & DM preference & money demand elasticity -0.3564 & 0.3376 \\
\hline$k$ & search cost & price dispersion 0.035 & 0.01 \\
\hline
\end{tabular}

Table 1: Baseline Calibration

Figure 4 presents the model-generated money demand function versus real data. The model performs less satisfactory when $i$ approaches the zero lower bound, due to the tension between the money demand and the price dispersion target. In order to generate enough demand for money when $i$ is close to zero, we need buyers to have elastic demand for the DM goods. On the other hand, when sellers face such buyers, they tend to lower the DM prices, which causes the price distribution to be less dispersed.

Figure 5a presents the relation between inflation, average price, and the upper and lower limit of $F$. The kink of $\bar{p}$ represents the point where type- 1 buyer's cash constraint starts to bind in the DM and they have to spend all their money. It happens when inflation gets high and carrying money becomes costly enough. As we explained earlier, the real balance 


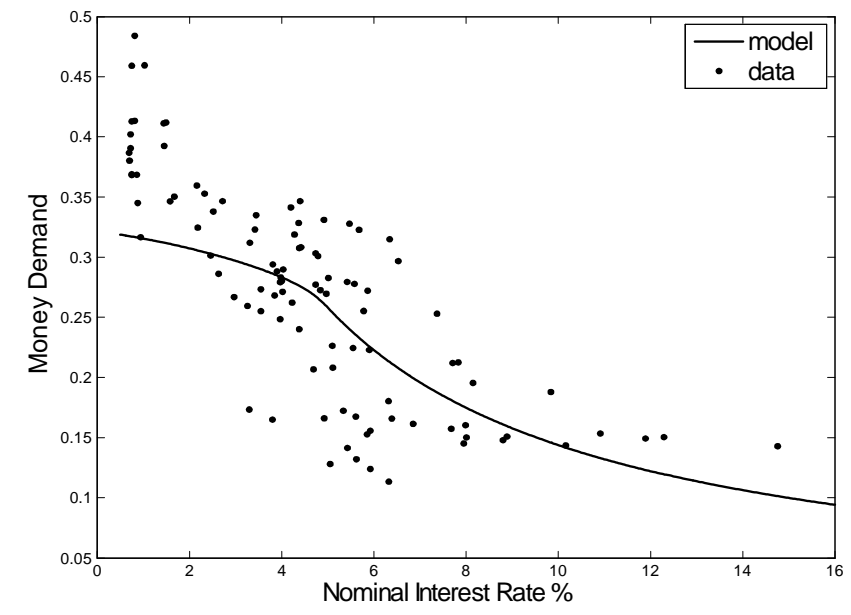

Figure 4: Money Demand: Model and Data
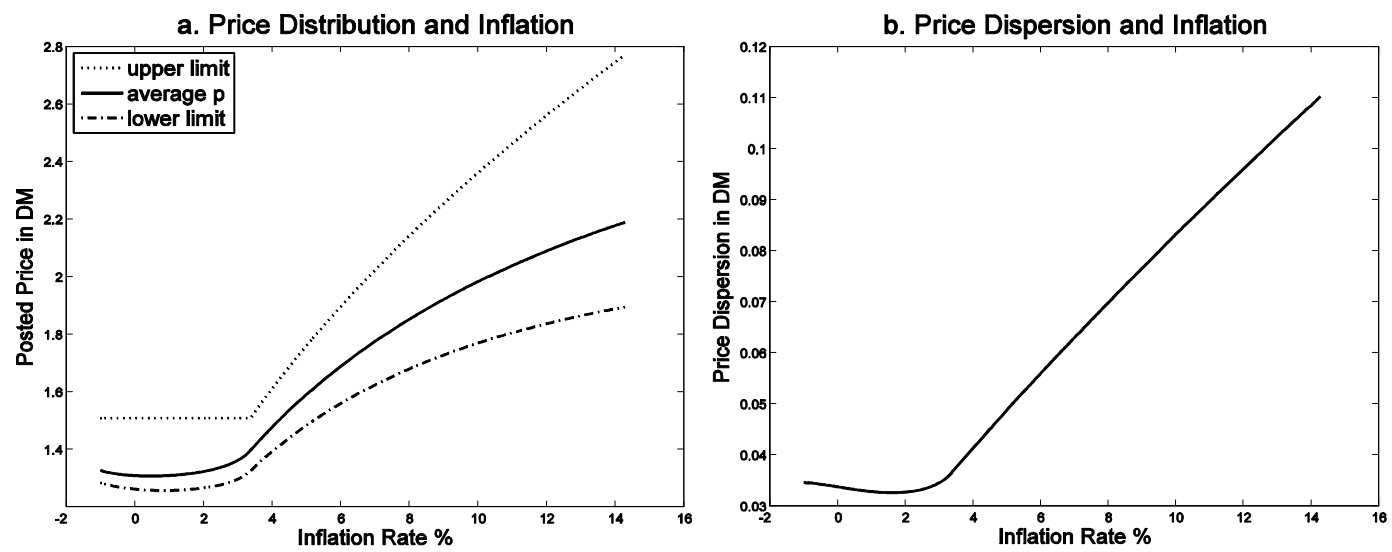

Figure 5: The Effects of Inflation on Prices

channel and the search channel have opposite effects on prices. Consequently, as shown in Figure 5, inflation has a non-monotonic effect on $\underline{p}$ and average price. The same cause also yields a non-monotonic relation between inflation and price dispersion. In our model, $F(p)$ increases with inflation, in the sense of first-order stochastic dominance. Hence, the degree of price dispersion eventually increases with inflation, as shown in Figure 5b. While Parsley (1996) and Debelle and Lamont (1997) document a positive relation between inflation and price dispersion, Caglayana et al. (2008) find the relationship to be U-shaped, and our result is generally consistent with their findings.

Figure 6 shows the relationship between inflation and total output. Not surprisingly, our model predicts an overall negative effect, except for a tiny increase around zero inflation. Total output decreases by about $18 \%$ as inflation increases to $10 \%$. Different from many 

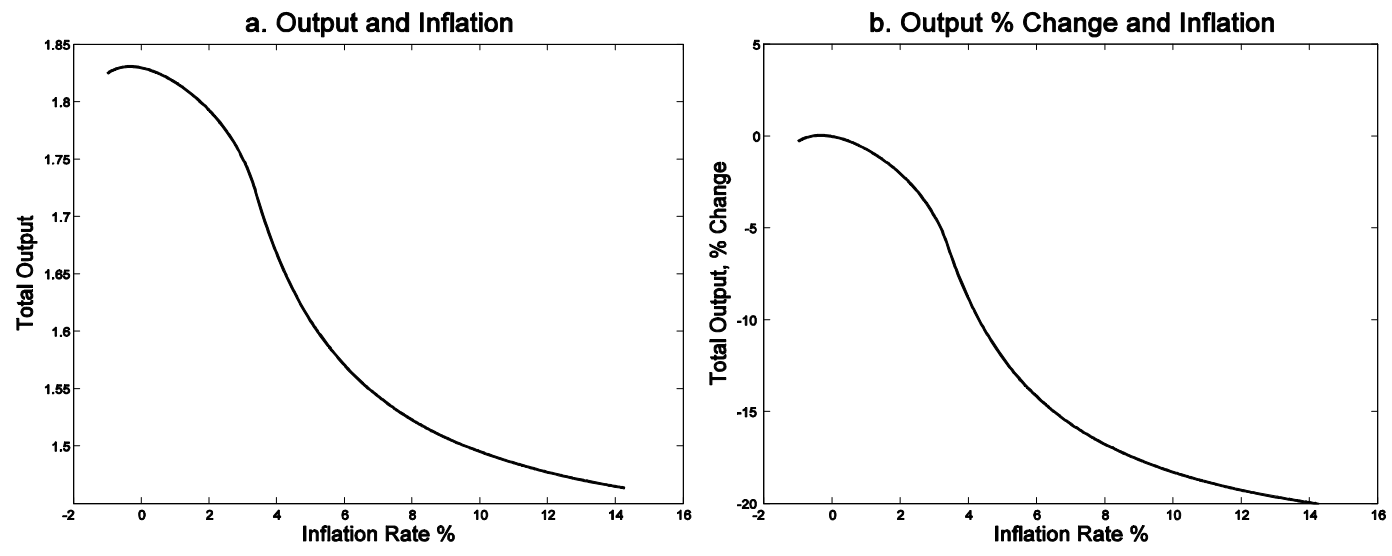

Figure 6: The Effect of Inflation on Total Output

other papers studying the negative impact of inflation on GDP, in our model, the output drop is purely driven by liquidity shortage and happens only in the DM.

\section{Welfare Cost of Inflation}

Following Lucas (2000), we measure the welfare cost of increasing inflation from zero to $\tau$ percent by compensating consumption. For any $\tau$, total welfare is given by

$$
\begin{aligned}
(1-\beta) \mathcal{W}(\tau)= & 2[v(x)-x]-\alpha k+(1-\alpha) \int_{\underline{p}}^{\bar{p}}\left[u\left(\frac{d\left(p ; z_{1}\right)}{p}\right)-c \frac{d\left(p ; z_{1}\right)}{p}\right] \mathrm{d} F(p) \\
& +\alpha \int_{\underline{p}}^{\bar{p}}\left[u\left(\frac{d\left(p ; z_{2}\right)}{p}\right)-c \frac{d\left(p ; z_{2}\right)}{p}\right] \mathrm{d}\left[1-(1-F(p))^{2}\right] .
\end{aligned}
$$

In (23), the first term $2[v(x)-x]$ is the total surplus from CM trade, and the two integral terms are the surplus from DM trade for type- 1 and type-2 buyers, subtracting search cost. We can also write the total welfare at zero inflation, with consumption reduced by a factor of $\Delta$, as follows

$$
\begin{aligned}
(1-\beta) \mathcal{W}_{\Delta}(0)= & 2[v(\Delta x)-x]-\alpha k+(1-\alpha) \int_{\underline{p}}^{\bar{p}}\left[u\left(\frac{\Delta d\left(p ; z_{1}\right)}{p}\right)-c \frac{d\left(p ; z_{1}\right)}{p}\right] \mathrm{d} F(p) \\
& +\alpha \int_{\underline{p}}^{\bar{p}}\left[u\left(\frac{\Delta d\left(p ; z_{2}\right)}{p}\right)-c \frac{d\left(p ; z_{2}\right)}{p}\right] \mathrm{d}\left[1-(1-F(p))^{2}\right] .
\end{aligned}
$$

We measure the welfare cost of $\tau$ percent inflation as the value $1-\Delta_{0}$ that solves $\mathcal{W}(\tau)=$ $\mathcal{W}_{\Delta_{0}}(0)$. This implies that every agent in the economy with zero inflation needs to give up 


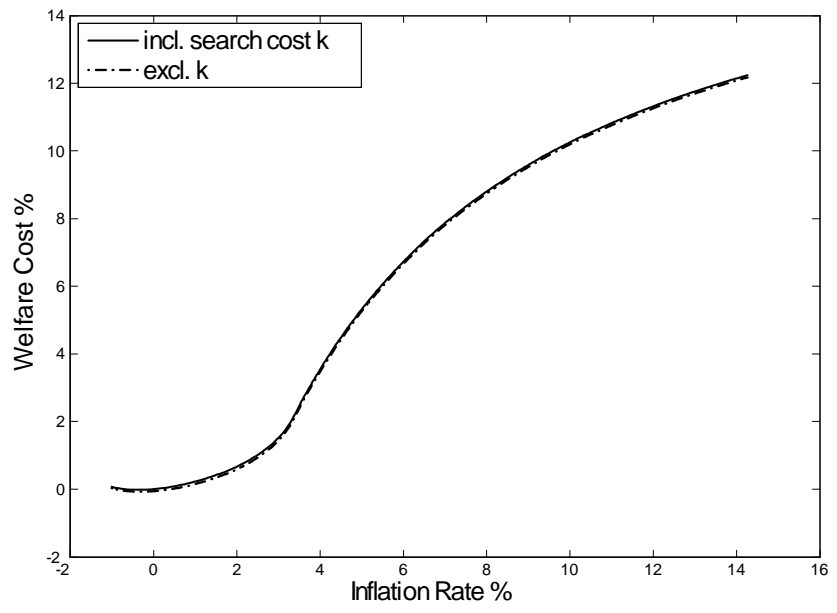

Figure 7: The Welfare Cost of Inflation

$1-\Delta_{0}$ percent of his consumption to move to the economy with $\tau$ percent inflation.

In the baseline calibration, we find the welfare cost of $10 \%$ annual inflation is worth $10.25 \%$ of the consumption in the economy with zero inflation, which is larger than earlier findings in Cooley and Hansen (1989), Lucas (2000), Lagos and Wright (2005), Craig and Rocheteau (2008a), and Rocheteau and Wright (2009). The aggregate effect of inflation on welfare is illustrated in Figure 7, with and without search cost. Obviously, search cost only generates a negligible welfare loss.

The effect of inflation on welfare is non-monotonic. Figure 7 shows that, due to an increase in $\alpha$, a small deviation from the Friedman rule actually leads to a small welfare increase. Even if it is costless to carry money, sellers still set prices above the marginal cost for the DM goods, just as Burdett and Judd (1984) show in a cashless economy. If the cost of holding money increases, more buyers want to search for low prices, so as to increase the marginal benefit of holding money. As $\alpha$ increases, the average transaction price drops due to increased competition among sellers, and thus welfare increases. On the other hand, buyers also respond to a larger $i$ by decreasing their money holdings, which will lower welfare. At the very low level of inflation, the positive effect through the search channel outweighs the negative effect through the real balance channel. As a result, welfare slightly increases. As the cost of holding money keeps increasing, buyers' money holdings drop fast, and the first-order effect of this cost on consumption quickly dominates the search channel. Sellers respond to lower $z_{1}$ and $z_{2}$ by posting higher prices, and the average price increases, which magnifies the negative effect on welfare through decreasing consumption. 
Consequently, Figure 7 displays a range of rapid increase in welfare cost, from $3 \%$ to $10 \%$ inflation.

\subsection{Welfare Cost Decomposition}

As discussed in Section 3.4, $z, \alpha$, and $F$ directly affect welfare by entering the welfare equation (23). Each channel also has an indirect general equilibrium effect on welfare by affecting other endogenous variables, which is the interaction of different channels. In order to study the direct effect of each individual channel and their interaction, we use two methods to decompose the welfare cost.

\begin{tabular}{|c|c|c|c|c|}
\hline & $1 \%$ & $2 \%$ & $5 \%$ & $10 \%$ \\
\hline baseline & $0.23 \%$ & $0.67 \%$ & $5.32 \%$ & $10.25 \%$ \\
\hline real balance channel, direct effect (const. $z$ ) & $-0.096 \%$ & $0.066 \%$ & $3.96 \%$ & $8.36 \%$ \\
\hline real balance channel, total effect (exog. $z$ ) & $-0.013 \%$ & $-0.039 \%$ & $-0.097 \%$ & $-0.16 \%$ \\
\hline price posting channel, direct effect (const. $F$ ) & $0.37 \%$ & $0.71 \%$ & $4.01 \%$ & $7.91 \%$ \\
\hline price posting channel, total effect (exog. $F$ ) & $0.5 \%$ & $0.71 \%$ & $1.34 \%$ & $2.37 \%$ \\
\hline search channel, direct effect (const. $\alpha)$ & $0.25 \%$ & $0.7 \%$ & $5.35 \%$ & $10.29 \%$ \\
\hline search channel, total effect (exog. $\alpha)$ & $2.45 \%$ & $5.05 \%$ & $10.28 \%$ & $14.37 \%$ \\
\hline
\end{tabular}

Table 2: Welfare Cost Decomposition

In method 1, we mechanically replace the equilibrium value of one variable with a constant, and recalculate the welfare cost of this "fake" equilibrium without resolving the model. We consider the economy with the minimum inflation rate as the benchmark, and $z_{0}, \alpha_{0}$, and $F_{0}$ denote its equilibrium solution, where $z_{0}$ is a vector, denoting the optimal real balance of both buyer types. We replace the equilibrium values of $z, \alpha$, and $F$ at different inflation rates with a constant $z_{0}, \alpha_{0}$, and $F_{0}$, one variable at a time. When recalculating the welfare cost, we can successfully isolate the direct effect through an individual channel by holding that channel constant. In method 2, we completely shut down an endogenous variable by giving it an exogenous value, and then resolve the model. We shut down $z, \alpha$, and $F$ one at a time by imposing $z=z_{0}, \alpha=\alpha_{0}$, and $F=F_{0}$, respectively. Then, we resolve the constrained equilibrium at different inflation rates and recalculate the welfare cost. By doing this, we can successfully isolate the total effect of each channel, including the direct and indirect effect on welfare. Figure 8 compares the welfare cost of inflation in the original economy with different decompositions, and Table 2 presents the welfare cost at four different inflation rates. 
Figure $8 \mathrm{a}$ shows the outcome when we use method 1 to decompose the real balance channel. The dashed curve represents the welfare cost of inflation when $z$ is replaced by a constant $z_{0}$, and the difference between the two curves is the direct effect of inflation on welfare through $z$. From Table 2, we can see that the welfare cost of $10 \%$ inflation drops by $2 \%$. Figure $8 \mathrm{~b}$ shows the welfare cost of inflation when we use method 2 to make $z$ an exogenous variable with value $z_{0}$. We find that the welfare cost of inflation completely disappears, and actually there is a tiny welfare gain due to increased $\alpha$. This result shows that, in this model, the opportunity cost of holding money plays the lead role in generating a large welfare loss, mostly through the general equilibrium aspect by affecting $F$ and $\alpha$.

Next, Figure $8 \mathrm{c}$ and $8 \mathrm{~d}$ present the welfare decomposition for the price posting channel, using method 1 and 2, respectively. The direct effect through the price posting channel at $10 \%$ inflation is about $2 \%$, and it is in the range of what Burstein and Hellwig (2008) find in a New Keynesian menu cost model with monopolistically competitive firms. When we completely shut down the price posting channel and make $F$ exogenous, the welfare cost of $10 \%$ inflation significantly drops to $2.37 \%$. This value mainly captures the effect through the real balance channel alone. It is larger than the earlier findings in Cooley and Hansen (1989) and Lucas (2000), at the high end of Burstein and Hellwig (2008), and at the low end of Lagos and Wright (2005), Craig and Rocheteau (2008a), and Rocheteau and Wright (2009).

Finally, regarding the search channel, (23) shows that it can directly improve welfare by increasing the measure of type-2 buyers. As shown in Figure 8e and Table 2, this effect of the search channel is negligible, generally less than $0.1 \%$. On the other hand, the search channel affects welfare greatly by interacting with the other two channels. This general equilibrium effect is illustrated by an elevated welfare cost curve in Figure $8 \mathrm{f}$ after making search exogenous. Table 2 shows that endogenous search can lower the welfare cost by almost $50 \%$.

Based on the decomposition exercise, we can conclude that, the source of the large welfare cost generated by the model lies in the interaction of the real balance and the price posting channel. As we explained earlier, buyers carry less money as the opportunity cost of holding money increases. Since the buyer's elasticity of expenditure is less than one, sellers respond by posting higher prices, in order to earn more profit from cash-constrained buyers. Higher prices lower the marginal benefit of carrying money, and buyers reduce their money holdings 
a. Constant Real Balance

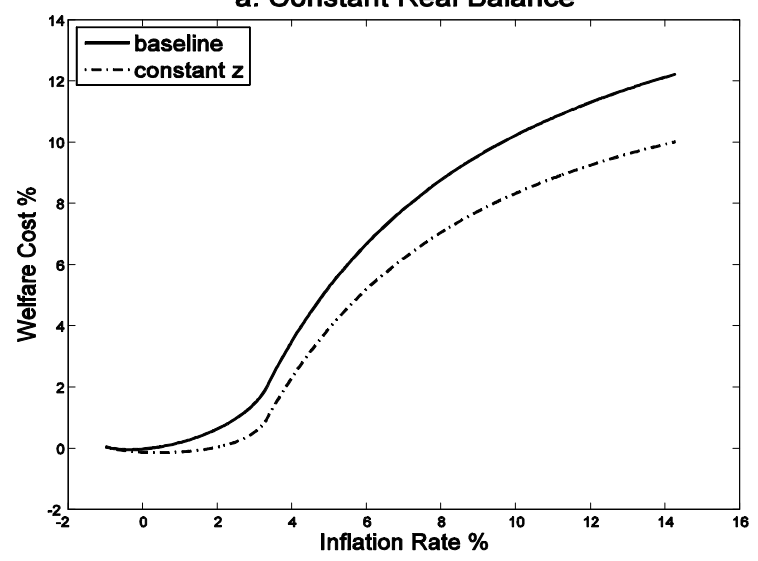

c. Constant Price Distribution

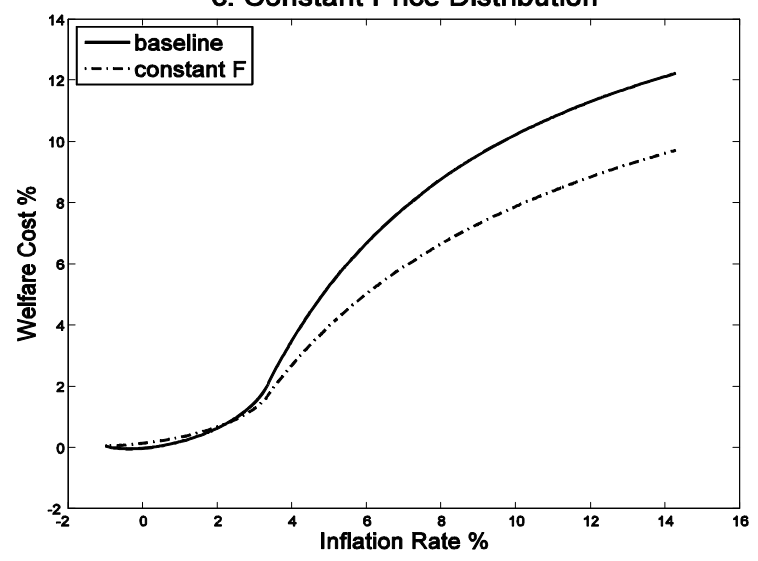

e. Constant Search Intensity

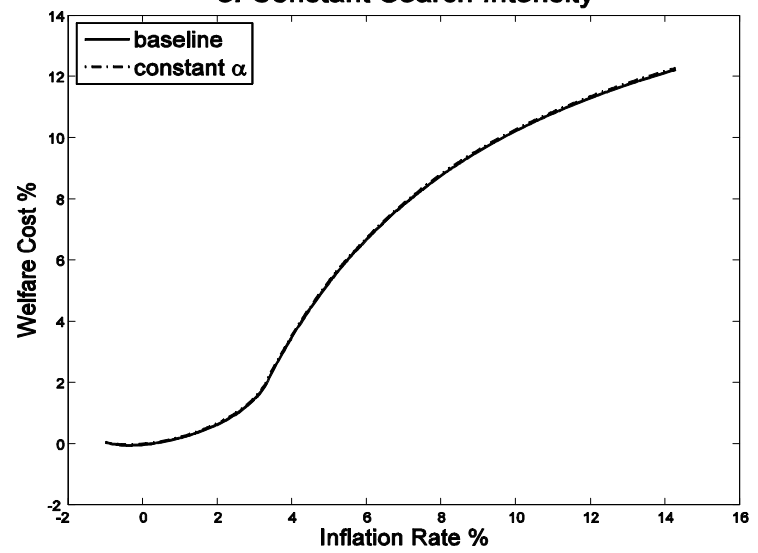

b. Exogenous Real Balance

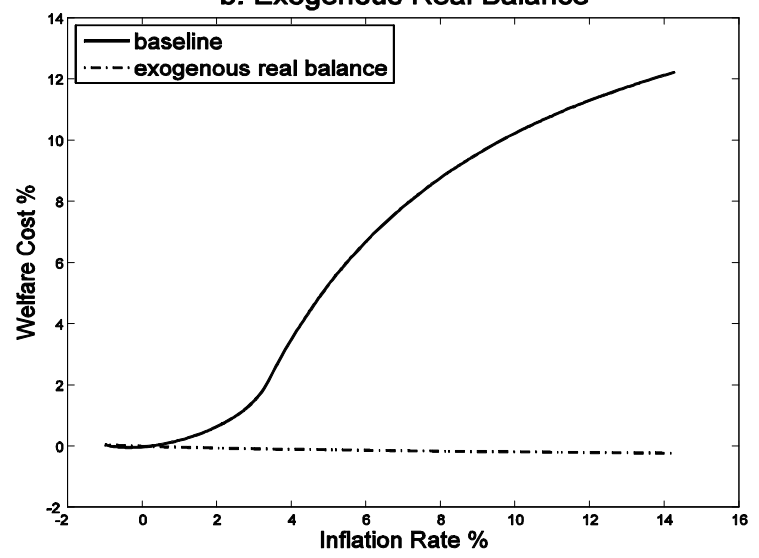

d. Exogenous Price Distribution

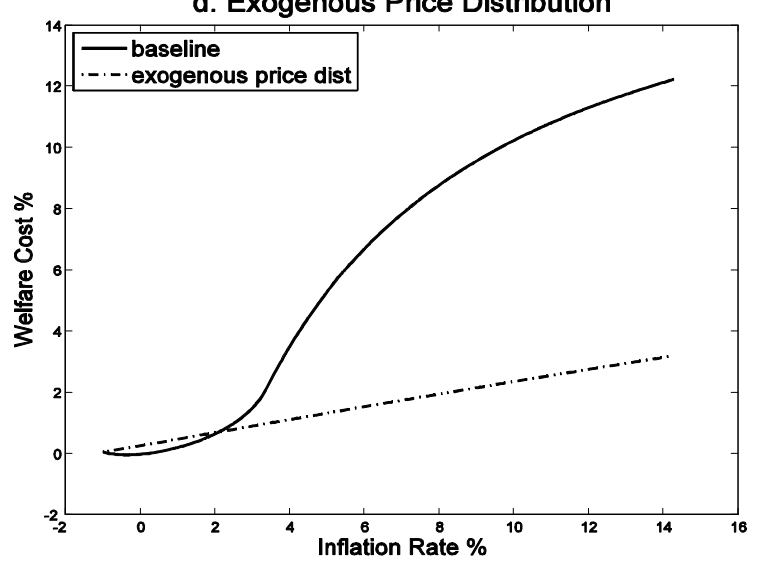

f. Exogenous Search Intensity

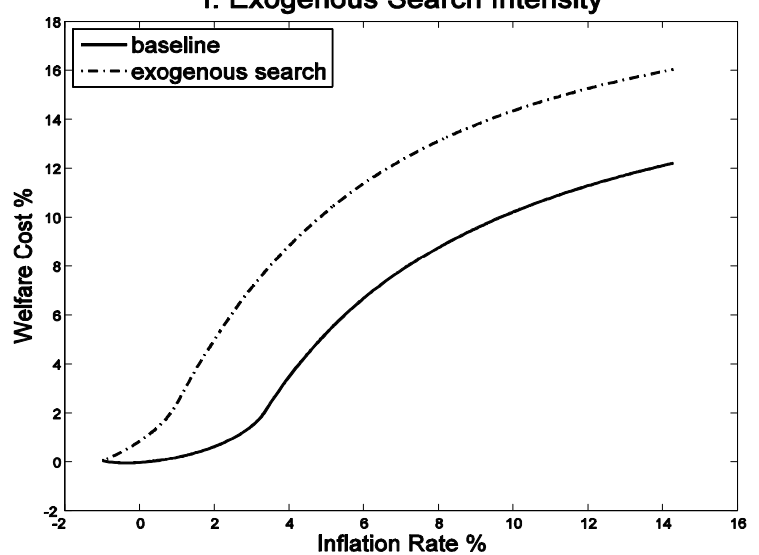

Figure 8: Welfare Cost Decomposition 
even further. This feedback effect between $z$ and $F$ greatly decreases the DM consumption. Its negative impact on welfare is even larger than the holdup problem in generalized Nash bargaining. As pointed out by Lagos and Wright (2005), bargaining can generate a big welfare cost, because the buyer's investment in the DM trade, by holding money under the inflation tax, is not fully compensated by the bargaining outcome, unless the buyer's bargaining power is one. In the current model with price posting, as inflation increases, the total surplus from the DM trade decreases due to lower $z$, and the buyer's share of the DM trade surplus also decreases due to higher posted prices. This is equivalent to decreasing the buyer's bargaining power with rising inflation as in Lagos and Wright (2005), which makes the holdup problem even more severe. This is why the welfare cost in our baseline calibration is much larger.

In the appendix, we apply an extension of the model to measure the welfare gain of smoothing monetary shocks. The stochastic money supply process is estimated from the U.S. M1 data. We find that the gain of eliminating monetary shocks is worth $0.15 \%$ of consumption in the benchmark economy, a little larger than the previous findings in Lucas (1987) and Faig and Li (2009). In our model, the interaction of different channels amplifies the effect of both trend inflation and inflation fluctuations on welfare, but the latter is still much less important in a quantitative sense, only contributing less than $3 \%$ to the total welfare loss.

\subsection{Robustness}

We calibrate the model to a shorter post-war period of 1950-2000 and consider both annual and quarterly frequencies. Table 3 compares the welfare cost of inflation across three different calibrations. We find that the longer annual sample generates a larger welfare cost than the shorter quarterly sample. The post-war data features a lower average money demand and a higher elasticity, which predicts a larger $A$ and a smaller $\sigma$ in calibration. This implies the DM share in total output is higher in the baseline calibration, and the elasticity of demand is lower. Both factors contribute to the larger welfare cost found in the baseline calibration.

In order to better understand the relation between the parameters and the welfare results, we vary the values of $A, \sigma$, and $k$ over a reasonable range, and recalculate the welfare cost of inflation. The results are presented in Table 4 . We find that the welfare cost is larger with smaller values of $A$, which characterizes the relative size of the DM and the CM output. If 
$A$ is big, the share of the DM output in total production is small, and changes in the DM output caused by higher inflation have a small effect on total welfare. Table 4 also shows that the welfare cost increases with $\sigma$. As $\sigma$ gets bigger, the buyer's price elasticity of demand for the DM goods decreases. Even if inflation makes carrying money more costly, buyers do not want to substitute DM consumption with CM consumption, and, thus, inflation creates a large distortion. When sellers face buyers with inelastic demand, they post higher prices, get more profit, and welfare decreases.

\begin{tabular}{|c|c|c|c|c|}
\hline & $1 \%$ & $2 \%$ & $5 \%$ & $10 \%$ \\
\hline baseline & $0.23 \%$ & $0.67 \%$ & $5.32 \%$ & $10.25 \%$ \\
\hline annual 1950-2000 & $0.12 \%$ & $0.33 \%$ & $2.08 \%$ & $5.02 \%$ \\
\hline quarterly 1950-2000 & $-0.02 \%$ & $0.07 \%$ & $0.75 \%$ & $3.19 \%$ \\
\hline
\end{tabular}

Table 3: Welfare Cost, Time Period and Frequency

There is a non-monotonic effect of $k$ on welfare cost. This is because $k$ most directly affects $\alpha$ in (21) and the gain of observing two prices in that equation is non-monotonic in $\alpha$. In the computational exercises, we find that the slope of $\Phi(\alpha)$ with respect to $\alpha$ changes, depending on different parameter values and nominal interest rates, because $\alpha$ enters $\Phi(\alpha)$ indirectly through affecting $z$ and $F$. As a result, the overall effect of $\alpha$ on $\Phi(\alpha)$ is ambiguous, and so is the effect of $k$ on welfare.

Table 5 presents the effect of changing parameter values on welfare decomposition. We focus on $10 \%$ inflation. Each column represents a different parameter value, and each row stands for a different decomposition. By comparing the first three rows, we see that, although the direct effect of $z$ on welfare is sometimes limited, when we completely shut down the real balance channel, the welfare cost drops sharply to a negligible level. The welfare gains in the third row are caused by an increase in $\alpha$. A similar pattern can be observed with the price posting panel. $F$ affects welfare both directly and indirectly, and the magnitude of the indirect effect is larger than the direct one. Still, when compared with the real balance channel, the general equilibrium effect of $F$ on welfare is much smaller. Looking at the last two rows of Table 5, the direct effect of $\alpha$ on welfare is always negligible, and its indirect effect is always positive, except for $\sigma=0.7$. In that case, the equilibrium value of $\alpha$ at $10 \%$ inflation is actually smaller than in the benchmark economy, which causes a welfare gain when we shut down the search channel. 
Finally, from the above analysis we conclude the following: the real balance channel is the source of the welfare cost in our model; the interaction of the real balance and the price posting channel is the key to generating a sizable welfare cost; and the general equilibrium effect of each channel is always larger than the direct effect.

\begin{tabular}{|c|c|c|c|c|}
\hline & $1 \%$ & $2 \%$ & $5 \%$ & $10 \%$ \\
\hline baseline & $0.23 \%$ & $0.67 \%$ & $5.32 \%$ & $10.25 \%$ \\
\hline$A=0.01$ & $0.74 \%$ & $2.23 \%$ & $17.56 \%$ & $33.36 \%$ \\
\hline$A=10$ & $0.02 \%$ & $0.06 \%$ & $0.52 \%$ & $1.02 \%$ \\
\hline$\sigma=0.2$ & $0.06 \%$ & $0.16 \%$ & $0.77 \%$ & $3.29 \%$ \\
\hline$\sigma=0.7$ & $27.6 \%$ & $38.51 \%$ & $49.61 \%$ & $54.57 \%$ \\
\hline$k=0.0001$ & $-0.78 \%$ & $0.52 \%$ & $0.99 \%$ & $1.14 \%$ \\
\hline$k=0.02$ & $-0.02 \%$ & $0.02 \%$ & $0.34 \%$ & $2.32 \%$ \\
\hline
\end{tabular}

Table 4: Welfare Cost, Parameter Values

\begin{tabular}{|c|c|c|c|c|c|c|c|}
\hline & baseline & $A=0.01$ & $A=10$ & $\sigma=0.2$ & $\sigma=0.7$ & $k=0.0001$ & $k=0.02$ \\
\hline no decomp. & $10.25 \%$ & $33.36 \%$ & $1.02 \%$ & $3.28 \%$ & $54.57 \%$ & $1.14 \%$ & $2.32 \%$ \\
\hline real balance, direct(const. $z$ ) & $8.36 \%$ & $27.36 \%$ & $0.83 \%$ & $1.2 \%$ & $54.21 \%$ & $1.07 \%$ & $0.41 \%$ \\
\hline real balance, total(exog. $z$ ) & $-0.16 \%$ & $-0.55 \%$ & $-0.02 \%$ & $-0.13 \%$ & $-2.52 \%$ & $-20.46 \%$ & $-0.31 \%$ \\
\hline price posting, direct(const. $F$ ) & $7.91 \%$ & $25.92 \%$ & $0.78 \%$ & $3.03 \%$ & $30.61 \%$ & $0.33 \%$ & $2.24 \%$ \\
\hline price posting, total(exog. $F$ ) & $2.37 \%$ & $7.88 \%$ & $0.23 \%$ & $1.93 \%$ & $0.72 \%$ & $-17.14 \%$ & $2.02 \%$ \\
\hline search, direct (const. $\alpha)$ & $10.29 \%$ & $33.49 \%$ & $1.03 \%$ & $3.38 \%$ & $54.57 \%$ & $1.12 \%$ & $2.45 \%$ \\
\hline search, total $($ exog. $\alpha)$ & $14.37 \%$ & $46.09 \%$ & $1.46 \%$ & $5.56 \%$ & $40.31 \%$ & $1.01 \%$ & $5.94 \%$ \\
\hline
\end{tabular}

Table 5: Welfare Cost Decomposition, Parameter Values

\section{Conclusion}

In this paper, we developed a New Monetarist model to incorporate real balance, price posting, and endogenous search. We used the model to quantify the welfare cost of inflation, and studied different channels through which inflation affects welfare. Calibrating the model to match the U.S. data on money demand and price dispersion, we found that the welfare cost of $10 \%$ annual inflation is worth $10.25 \%$ of consumption in an economy with zero inflation. Our estimate is larger than previous findings in the literature. However, if either the real balance or the price posting channel is shut down, the welfare cost significantly decreases to a negligible level, which is consistent with earlier findings. 
In our model, inflation affects welfare most directly by increasing the opportunity cost of holding money. The effect through the real balance channel alone is limited, and the large welfare loss is driven by its interaction with the price posting channel. With higher inflation, buyers respond by holding less money, and sellers respond by posting higher prices. The general equilibrium effect through the two channels reduces consumption and welfare significantly. The search channel improves welfare mostly by increasing competition among sellers and lowering prices in the market. Its direct effect on welfare is tiny. The overall effect of inflation on welfare through the three channels is non-monotonic.

This paper modeled search frictions as the only driving force for buyers to hold money and sellers to post prices. Search frictions are also the source of endogenous price dispersion in equilibrium. This modeling choice is useful in incorporating different channels into one unified environment. There are other frictions that affect seller's price setting behavior and price dispersion, such as menu costs. In a related paper, Burdett and Menzio (2014) show that both menu costs and search frictions contribute to price dispersion, but search frictions are more important than menu costs in matching empirical data. However, in the context of the welfare cost of inflation, the relative importance of menu costs and search frictions has not been established. This relationship, especially considering their interactions, is a topic for future research. 


\section{References}

[1] Aruoba, S. Boragan, and Frank Schorfheide. (2011) "Sticky Prices versus Monetary Frictions: An Estimation of Policy Trade-Offs." American Economic Journal: Macroeconomics 3, 60-90.

[2] Bailey, Martin J. (1956) "The Welfare Cost of Inflationary Finance." Journal of Political Economy 64, 93-110.

[3] Benabou, Roland. (1988) "Search, Price Setting and Inflation." Review of Economic Studies 55, 353-376.

[4] Benabou, Roland. (1992) "Inflation and Efficiency in Search Markets." Review of Economic Studies 59, 299-329.

[5] Bethune, Zachary, Michael Choi, and Randall Wright. (2016) "Frictional Goods Markets: Theory and Applications." mimeo.

[6] Burdett, Kenneth and Kenneth L. Judd. (1983) "Equilibrium Price Dispersion." Econometrica 51, 955-969.

[7] Burdett, Kenneth and Guido Menzio. (2014) "The (Q,S,s) Pricing Rule." NBER Working Paper 19094.

[8] Burstein, Ariel and Christian Hellwig. (2008) "Welfare Costs of Inflation in a Menu Cost Model." American Economic Review 98, 438-443.

[9] Caglayan, Mustafa, Alpay Filiztekin, and Michael Rauh. (2008) "Inflation, Price Dispersion, and Market Structure." European Economic Review 52, 1187-1208.

[10] Cooley, F. Thomas and Gary D. Hansen. (1989) "The Inflation Tax in a Real Business Cycle Model." American Economic Review 79, 733-748.

[11] Craig, Ben and Guillaume Rocheteau. (2008a) "Inflation and Welfare: A Search Approach." Journal of Money, Credit and Banking 40, 89-119.

[12] Craig, Ben and Guillaume Rocheteau. (2008b) "State-dependent Pricing, Inflation, and Welfare in Search Economies." European Economic Review 52, 441-468.

[13] Cynamon, Barry, Donald Dutkowsky, and Barry Jones (2006) "Redefining the Monetary Aggregates: A Clean Sweep." Eastern Economic Journal 32, 661-72. 
[14] Debelle, Guy and Owen Lamont. (1997) "Relative Price Variability and Inflation: Evidence from U.S. Cities." Journal of Political Economy 105, 132-152.

[15] Diamond, Peter A. (1993). "Search, Sticky Prices, and Inflation." Review of Economic Studies 60, 53-68.

[16] Dutu, Richard, Benoit Julien, and Ian King. (2012) "On the Welfare Gains of Price Dispersion." Journal of Money, Credit and Banking 44, 757-786.

[17] Faig, Miquel and Belen Jerez. (2005) "A Theory of Commerce." Journal of Economic Theory 122, 60-99.

[18] Faig, Miquel and Zhe Li. (2009) "The Welfare Costs of Expected and Unexpected Inflation." Journal of Monetary Economics 56, 1004-1013.

[19] Friedman, Milton and Anna Schwartz. (1963) A Monetary History of the United States, 1867-1960. Princeton University Press.

[20] Friedman, Milton and Anna Schwartz. (1982) "The Effect of the Term Structure of Interest Rates on the Demand for Money in the United States." Journal of Political Economy 90, 201-212.

[21] Head, Allen and Alok Kumar. (2005) "Price Dispersion, Inflation, and Welfare." International Economic Review 46, 533-572.

[22] Head, Allen, Lucy Liu, Guido Menzio and Randall Wright. (2012) "Sticky Prices: A New Monetarist Approach." Journal of the European Economic Association 10, 939-973.

[23] Kaplan, Greg and Guido Menzio. (2015) "The Morphology of Price Dispersion." International Economic Review 56, 1165-1206.

[24] Lerner, William. (1970) Historical Statistics of the United States, Colonial Times to 1970. Bureau of the Census, United States Department of Commerce.

[25] Lagos, Ricardo and Randall Wright. (2005) "A Unified Framework for Monetary Theory and Policy Analysis." Journal of Political Economy 113, 463-484.

[26] Liu, Lucy, Liang Wang and Randall Wright. (2015) "Sticky Prices and Costly Credit." UH Department of Economics Working Paper 15-05.

[27] Lucas, Robert, Jr. (1987) Models of Business Cycles. Basil Blackwell, New York.

[28] Lucas, Robert, Jr. (2000) "Inflation and Welfare." Econometrica 68, 247-274. 
[29] Lucas, Robert, Jr. and Juan Nicolini (2015) "On the Stability of Money Demand". Journal of Monetary Economics 73, 48-65.

[30] Parsley, David C. (1996) "Inflation and Relative Price Variability in the Short and Long Run: New Evidence from the United States." Journal of Money, Credit and Banking 28, 323-341.

[31] Rocheteau, Guillaume and Randall Wright. (2005) "Money in Search Equilibrium, in Competitive Equilibrium, and in Competitive Search Equilibrium." Econometrica 73, 175-202.

[32] Rocheteau, Guillaume and Randall Wright. (2009) "Inflation and Welfare in Models with Trading Frictions." in Monetary Policy in Low Inflation Economies, edited by David E. Altig and Ed Nosal, pp. 89-116. New York: Cambridge University Press.

[33] Shi, Shouyong. (1997) "A Divisible Search Model of Fiat Money." Econometrica 65, $75-102$.

[34] Tarski, Alfred. (1955) "A Lattice Theoretical Fixpoint Theorem and Its Applications." Pacific Journal of Mathematics 5, 285-309.

[35] Wright, Randall. (2010) "A Uniqueness Proof for Monetary Steady State." Journal of Economic Theory 145, 382-391.

[36] Wallace, Neil. (2011) "The Mechanism-Design Approach to Monetary Theory." in Handbook of Monetary Economics, vol 3A, edited by Benjamin M. Friedman and Michael Woodford, pp. 3-23. San Diego: North-Holland. 


\section{Appendix A: Proofs of Non-obvious Results}

\section{Proof of Lemma 1.}

The first order condition of the buyer's unconstrained optimization problem is $u^{\prime}\left(d^{*} / p\right) / p-$ $1=0$. Notice that $\sigma<1$ implies $-q u^{\prime \prime}(q) / u^{\prime}(q)<1$, so $u^{\prime}\left(d^{*} / p\right) / p$ is a decreasing function in $p$ and $\partial d^{*}(p) / \partial p<0$. Hence, there exists $\tilde{p}_{j}$ such that $d^{*}\left(\tilde{p}_{j}\right)=z_{j}$ for $z_{j}>0, j=1,2$. For $p<\tilde{p}_{j}, d^{*}(p)>z_{j}$ and $u^{\prime}\left(z_{j} / p\right) / p-1>0$. Buyers want to spend more, but are subject to the constraint $d^{*}\left(p ; z_{j}\right) \leq z_{j}$. Hence, $d^{*}\left(p ; z_{j}\right)=z_{j}$ for $p<\tilde{p}_{j}$. For $p \geq \tilde{p}_{j}, d^{*}(p) \leq z_{j}$ and $d^{*}\left(p ; z_{j}\right)=d^{*}(p)$. It is straightforward to verify that $\partial \tilde{p}_{j} / \partial z_{j}<0$.

\section{Proof of Lemma 2.}

In this proof, I use $z_{j}^{*}>0, j=1,2$ to denote the optimal real balance of type- 1 and type- 2 buyers, respectively. In the following, we focus on type-1 buyers and the proof for type- 2 buyers can be derived similarly. We proceed by contradiction and assume that $\tilde{p}_{1} \leq \underline{p}$ at $z_{1}^{*}$. We first consider the situation in which $\tilde{p}_{1}<\underline{p}$. If $\tilde{p}_{1}<\underline{p}, d^{*}\left(p ; z_{1}\right)=d^{*}(p)$ for all $p \in[\underline{p}, \bar{p}]$. We plug it into (13) and omit all the terms unrelated to $z_{1}$, and the buyer's optimization problem can be rewritten as

$$
L=\max _{z_{1}}\left\{-i z_{1}+\int_{\underline{p}}^{\bar{p}}\left[u\left(\frac{d^{*}(p)}{p}\right)-d^{*}(p)\right] \mathrm{d} F(p)\right\} .
$$

The first order condition with respect to $z_{1}$ evaluated at $z_{1}^{*}$ is $\partial L / \partial z_{1}^{*}=-i<0$, which is a contradiction to $z_{1}^{*}$ being the optimal real balance. Then, we consider the situation of $\tilde{p}_{1}=\underline{p}$. Recall that $\tilde{p}_{1}$ is determined by $z_{1}$ through $u^{\prime}\left(z_{1} / \tilde{p}_{1}\right)=\tilde{p}_{1}$, so $z_{1}^{*}$ satisfies $\tilde{p}\left(z_{1}^{*}\right)=\underline{p}$. We want to solve for $\partial L / \partial z_{1}^{*}$. When $z_{1}$ approaches $z_{1}^{*}$ from below, $\tilde{p}\left(z_{1}\right)$ approaches $\underline{p}$ from above since $\partial \tilde{p}_{1} / \partial z_{1}<0$, and we can rewrite $(24)$ as

$$
\begin{aligned}
L= & \max _{z_{1}}\left\{-i z_{1}+\int_{\tilde{p}_{1}}^{\bar{p}}\left[u\left(\frac{d^{*}(p)}{p}\right)-d^{*}(p)\right] \mathrm{d} F(p)\right. \\
& \left.+\int_{\underline{p}}^{\tilde{p}_{1}}\left[u\left(\frac{z_{1}}{p}\right)-z_{1}\right] \mathrm{d} F(p)\right\}
\end{aligned}
$$

thus $\lim _{z_{1} \rightarrow z_{1-}^{*}} \partial L / \partial z_{1}=\lim _{z_{1} \rightarrow z_{1-}^{*}}\left\{-i+\int_{\underline{p}}^{\tilde{p}_{1}}\left[u^{\prime}\left(z_{1} / p\right) / p-1\right] \mathrm{d} F(p)\right\}=-i<0$. On the other hand, when $z_{1}$ approaches $z_{1}^{*}$ from above, $\tilde{\tilde{p}}\left(z_{1}\right)$ approaches $\underline{p}$ from below, and $\lim _{z_{1} \rightarrow z_{1+}^{*}} \partial L / \partial z_{1}=$ $-i<0$. However, the fact that $z_{1}^{*}$ is the optimal real balance implies $\lim _{z_{1} \rightarrow z_{1-}^{*}} \partial L / \partial z_{1} \geq 0$ and $\lim _{z_{1} \rightarrow z_{1+}^{*}} \partial L / \partial z_{1} \leq 0$. This is a contradiction. Therefore, we must have $\tilde{p}_{1}>\underline{p}$ for type-1 buyers.

\section{Proof of Lemma 3.}


The optimal real balances for type- 1 and type- 2 buyers, $z_{1}^{*}$ and $z_{2}^{*}$, satisfy the following condition.

$$
\int_{\underline{p}}^{\tilde{p}_{2}}\left[u^{\prime}\left(\frac{z_{2}^{*}}{p}\right) \frac{1}{p}-1\right] \mathrm{d}\left[1-(1-F(p))^{2}\right]=\int_{\underline{p}}^{\tilde{p}_{1}}\left[u^{\prime}\left(\frac{z_{1}^{*}}{p}\right) \frac{1}{p}-1\right] \mathrm{d} F(p)
$$

Let $\hat{F}(p)=1-[1-F(p)]^{2}$ and $\zeta(z, p)=u^{\prime}(z / p) / p-1$. We proceed by contradiction. Suppose $z_{1}^{*} \geq z_{2}^{*}$, then

$$
\begin{aligned}
& \int_{\underline{p}}^{\tilde{p}_{2}}\left[u^{\prime}\left(\frac{z_{2}^{*}}{p}\right) \frac{1}{p}-1\right] \mathrm{d}\left[1-(1-F(p))^{2}\right] \\
\geq & \int_{\underline{p}}^{\tilde{p}_{1}}\left[u^{\prime}\left(\frac{z_{2}^{*}}{p}\right) \frac{1}{p}-1\right] \mathrm{d}\left[1-(1-F(p))^{2}\right] \\
\geq & \int_{\underline{p}}^{\tilde{p}_{1}}\left[u^{\prime}\left(\frac{z_{1}^{*}}{p}\right) \frac{1}{p}-1\right] \mathrm{d}\left[1-(1-F(p))^{2}\right] \\
> & \int_{\underline{p}}^{\tilde{p}_{1}}\left[u^{\prime}\left(\frac{z_{1}^{*}}{p}\right) \frac{1}{p}-1\right] \mathrm{d} F(p)
\end{aligned}
$$

where we have used the facts that $\tilde{p}_{2}>\tilde{p}_{1}$ due to $\partial \tilde{p} / \partial z<0, F(p)$ first-order stochastically dominates $\hat{F}(p)$, and $\zeta(z, p)$ is decreasing in $z$ and $p$, respectively, assuming $u$ satisfies $-q u^{\prime \prime}(q) / u^{\prime}(q)=\sigma<1$. (26) contradicts (25), and hence $z_{1}^{*}<z_{2}^{*}$.

\section{Proof of Lemma 4.}

First, notice that when $p=\bar{p}$ is posted, only type- 1 buyers purchase from this seller, since all the other prices are below $\bar{p}$. Given the expression for type- 1 worker's cutoff price $\tilde{p}_{1}$ in Lemma 1 , there are two cases: $\bar{p} \leq \tilde{p}_{1}$ or $\bar{p}>\tilde{p}_{1}$. If $\bar{p} \leq \tilde{p}_{1}, d^{*}\left(\bar{p} ; z_{1}\right)=z_{1}$, and $\pi(\bar{p})=z_{1}\left(1-\alpha^{*}\right)(1-c / \bar{p})$. A seller wants to choose a price as high as possible in the feasible range, and he posts $\bar{p}=\tilde{p}_{1}$. In the other case with $\bar{p}>\tilde{p}_{1}, d^{*}\left(\bar{p} ; z_{1}\right)=d^{*}(\bar{p})$ satisfying $u^{\prime}\left(d^{*}(\bar{p}) / \bar{p}\right)=\bar{p}$. The seller wants to choose $\bar{p}$ such that

$$
\left(1-\frac{c}{\bar{p}}\right) \frac{\partial d^{*}(\bar{p})}{\partial \bar{p}}+d^{*}(\bar{p}) \frac{c}{\bar{p}^{2}}=0,
$$

which is the first order condition of the seller's profit maximization problem. We can derive $\partial d^{*}(\bar{p}) / \partial \bar{p}$ from $u^{\prime}\left(d^{*}(\bar{p}) / \bar{p}\right)=\bar{p}$, and substitute it into $(27)$. Hence, if $\bar{p}>\tilde{p}_{1}, \bar{p}=\check{p}$ where $\check{p}$ is given by

$$
\frac{d^{*}(\check{p})}{\check{p}} u^{\prime \prime}\left(\frac{d^{*}(\check{p})}{\check{p}}\right)+\check{p}-c=0 .
$$

Therefore, the seller wants to post the upper limit $\bar{p}=\max \left\{\tilde{p}_{1}, \check{p}\right\}$. 


\section{Proof of Lemma 5.}

If $\alpha=0$, the seller's profit function is

$$
\pi(p)=d^{*}\left(p ; z_{1}\right)-c \frac{d^{*}\left(p ; z_{1}\right)}{p} .
$$

According to Lemma 4, there is a unique price that maximizes $\pi(p)$, so every seller posts $\bar{p}$. If a seller deviates by posting $\bar{p}^{\prime}=\bar{p}+\varepsilon$, where $\varepsilon>0$, his profit per trade decreases since $\bar{p}$ maximizes (28) and his trade volume stays the same. Similarly, if a seller deviates to $\bar{p}-\varepsilon$, his profit drops without an increase in trade volume. Therefore, there is no incentive for any seller to deviate away from $\bar{p}$.

If $\alpha=1$, it is clearly an equilibrium that every seller posts $p=c$. There is no incentive to post a price lower than $c$, since that yields a negative profit. On the other hand, if a seller deviates and posts $c+\varepsilon$, his profit $\pi(c+\varepsilon)$ is equal to zero since $F(c+\varepsilon)=1$ and he loses all the buyers. Next, I want to argue that this is the only equilibrium of the seller's price posting game. If there is another $F(p)$ concentrated at $p^{\prime}>c$, a seller has incentive to lower the posted price by $\varepsilon$, i.e., he wants to post $p^{\prime}-\varepsilon$. In this way, he can trade with a buyer for sure even though his profit from the trade decreases a little. A discrete increase in the trading probability makes up for the infinitesimal drop of the profit, and the seller's expected profit increases. Hence, there is a profitable deviation and another degenerate $F(p)$ does not exist. If there is another nondegenerate $F(p)$, its support $\mathcal{Z}_{F}$ is connected. This conclusion follows directly from Lemma 1 in Burdett and Judd (1983). $\pi(p)$ must be the same for all $p \in \mathcal{Z}_{F}$, and in particular $\pi(p)=\pi(\bar{p})=[2-2 F(\bar{p})]\left[d^{*}\left(\bar{p} ; z_{2}\right)-c d^{*}\left(\bar{p} ; z_{2}\right) / \bar{p}\right]=0$ since $F(\bar{p})=1$. However, for any $p$ such that $F(p) \in(0,1), \pi(p)=[2-2 F(p)]\left[d^{*}\left(p ; z_{2}\right)-c d^{*}\left(p ; z_{2}\right) / p\right]>0$. This is a contradiction. Therefore, $F(p)$ concentrated at $c$ is the unique equilibrium price distribution in the seller's price posting game.

If $\alpha^{*} \in(0,1)$, any $F(p)$ concentrated at $p \in[\underline{p}, \bar{p}]$ cannot be a price posting equilibrium distribution. There are two potential deviations for a seller. First, he may increase the price, hence increase the profit, while still keeping those buyers who only sample his price. Second, he can lower his price infinitesimally, and get a jump in the trading volume. When $\alpha^{*} \rightarrow 0$, the first deviation is preferred by the seller, and the second is preferable when $\alpha^{*} \rightarrow 1$. For intermediate values of $\alpha^{*}$, both can happen. Hence, $F(p)$ must be nondegenerate if $\alpha^{*} \in(0,1)$. Again from Lemma 1 in Burdett and Judd (1983), we know $F(p)$ is continuous 
with connected support. For any $p \in[\underline{p}, \bar{p}]$, we must have $\pi(p)=\pi(\bar{p})$, which implies

$$
\begin{aligned}
& (1-\alpha)\left[d^{*}\left(p ; z_{1}\right)-c \frac{d^{*}\left(p ; z_{1}\right)}{p}\right]+2 \alpha[1-F(p)]\left[d^{*}\left(p ; z_{2}\right)-c \frac{d^{*}\left(p ; z_{2}\right)}{p}\right] \\
= & (1-\alpha)\left[d^{*}\left(\bar{p} ; z_{1}\right)-c \frac{d^{*}\left(\bar{p} ; z_{1}\right)}{\bar{p}}\right] .
\end{aligned}
$$

The above equation determines a unique $F(p)$ for each $p$. In particular, $\pi(\underline{p})=\pi(\bar{p})$ determines $\underline{p}$, which satisfies

$$
(1-\alpha) d^{*}\left(\bar{p} ; z_{1}\right)\left(1-\frac{c}{\bar{p}}\right)=\left[(1-\alpha) d^{*}\left(\underline{p} ; z_{1}\right)+2 \alpha d^{*}\left(\underline{p} ; z_{2}\right)\right]\left(1-\frac{c}{\underline{p}}\right)
$$

\section{Proof of Proposition 1.}

First, we consider the case of $\alpha^{*}=0$. Suppose an SME exists for an economy with $\gamma>\beta$. Because $\alpha^{*}=0$, the equilibrium price distribution in the DM, $F^{*}(p)$ must be concentrated at $\bar{p}$.

When $\sigma<1, \bar{p}=\max \{\tilde{p}, \check{p}\}$. If $\check{p} \geq \tilde{p}, d^{*}\left(\bar{p} ; z_{1}^{*}\right)=d^{*}(\check{p})$. The type-1 buyer's optimal real balance $z_{1}^{*}$ maximizes

$$
L=-(\gamma-\beta) z_{1}+\beta\left[u\left(\frac{d^{*}(\check{p})}{\check{p}}\right)-d^{*}(\check{p})\right]
$$

Immediately, we have $\partial L / \partial z_{1}^{*}=-(\gamma-\beta)<0$, and $z_{1}^{*}=0$. This contradicts the existence of a monetary equilibrium. If $\tilde{p}>\check{p}, d^{*}\left(\bar{p} ; z_{1}^{*}\right)=z_{1}^{*}$, and $z_{1}^{*}$ maximizes

$$
L=-(\gamma-\beta) z_{1}+\beta\left[u\left(\frac{z_{1}}{\tilde{p}}\right)-z_{1}\right]
$$

Then, $\partial L / \partial z_{1}^{*}=-(\gamma-\beta)+\beta\left[u^{\prime}\left(z_{1}^{*} / \tilde{p}\right) / \tilde{p}-1\right]=-(\gamma-\beta)<0$, since $u^{\prime}\left(z_{1}^{*} / \tilde{p}\right)=\tilde{p}$ by Lemma 1. Hence, $z_{1}^{*}=0$ and it is again a contradiction. Therefore, there does not exist an SME with $\alpha^{*}=1$.

\section{Proof of Proposition 2.}

We want to show that there exists $\alpha^{*} \in(0,1), z_{1}^{*}>0, z_{2}^{*}>0$, and $F^{*}$ satisfying $\Phi\left(\alpha^{*}\right)=k,(14),(16)$, and Lemma (5). We first show that given $\alpha \in(0,1)$, there exists $z_{1}^{*}$, $z_{2}^{*}$, and $F^{*}$ such that type- 1 buyers choose $z_{1}=z_{1}^{*}$ and type- 2 buyers choose $z_{2}=z_{2}^{*}$ given the price distribution $F^{*}\left(p ; z_{1}^{*}, z_{2}^{*}\right)$. Then, we show that we can find $\alpha^{*} \in(0,1)$ such that $\Phi\left(\alpha^{*}\right)=k$. We proceed in four steps. 
Claim 1 Let $\underline{z}^{*}$ and $\bar{z}^{*}$ be defined by

$$
\tilde{p}\left(\underline{z}^{*}\right)=\check{p} \text { and } \tilde{p}\left(\bar{z}^{*}\right)=\underline{p},
$$

where $\check{p}$ is defined in Lemma (4) and $p$ is defined in

$$
\frac{(1+\alpha) d^{*}(\underline{p})}{(1-\alpha) d^{*}(\check{p})}=\frac{(\check{p}-c) \underline{p}}{(\underline{p}-c) \check{p}}
$$

Define $Z^{*}=\left(z_{1}^{*}, z_{2}^{*}\right)$. Then, for $Z_{0}^{*}=\left(z_{10}^{*}, z_{20}^{*}\right)$ and $Z_{1}^{*}=\left(z_{11}^{*}, z_{21}^{*}\right)$ such that $0<Z_{0}^{*}<$ $Z_{1}^{*} \leq\left(\bar{z}^{*}, \bar{z}^{*}\right), F\left(p ; Z_{0}^{*}\right)$ first-order stochastically dominates $F\left(p ; Z_{1}^{*}\right)$. For $Z_{0}^{*}$ and $Z_{1}^{*}$ such that $\left(\bar{z}^{*}, \bar{z}^{*}\right) \leq Z_{0}^{*}<Z_{1}^{*}$, then $F\left(p ; Z_{0}^{*}\right)=F\left(p ; Z_{1}^{*}\right)$.

Proof. First, consider the case in which $\left(\bar{z}^{*}, \bar{z}^{*}\right) \leq Z_{0}^{*}<Z_{1}^{*}$. Then, the price distribution is

$$
F\left(p ; Z^{*}\right)=1-\frac{1-\alpha}{2 \alpha}\left[\frac{d^{*}\left(\bar{p}^{*}\right)\left(\bar{p}^{*}-c\right) p}{d^{*}(p)(p-c) \bar{p}^{*}}-1\right]
$$

with support $\left[\underline{p}^{*}, \bar{p}^{*}\right]$, where $\bar{p}^{*}=\check{p}$ and $\underline{p}^{*}=\underline{p}$ as defined in $(29)$. In this case, $F\left(p ; Z_{0}^{*}\right)=$ $F\left(p ; Z_{1}^{*}\right)$ for all $Z_{0}^{*}$ and $Z_{1}^{*}$ such that $\left(\bar{z}^{*}, \bar{z}^{*}\right) \leq Z_{0}^{*}<Z_{1}^{*}$.

Second, consider the case $\underline{z}^{*} \leq z_{1 i}^{*} \leq \bar{z}^{*} \leq z_{2 i}^{*}$ for $i=0,1$ and $Z_{0}^{*}<Z_{1}^{*}$. In this case, the price distribution is

$$
F\left(p ; Z^{*}\right)= \begin{cases}1-\frac{1-\alpha}{2 \alpha}\left[\frac{d^{*}\left(\bar{p}^{*}\right)\left(\bar{p}^{*}-c\right) p}{d^{*}(p)(p-c) \bar{p}^{*}}-1\right] & \text { if } p \in\left[\tilde{p}\left(z_{1}^{*}\right), \bar{p}^{*}\right] \\ 1-\frac{1-\alpha}{2 \alpha}\left[\frac{d^{*}\left(\bar{p}^{*}\right)\left(\bar{p}^{*}-c\right) p}{d^{*}(p)(p-c) \bar{p}^{*}}-\frac{z_{1}^{*}}{d^{*}(p)}\right] & \text { if } p \in\left[\underline{p}^{*}, \tilde{p}\left(z_{1}^{*}\right)\right]\end{cases}
$$

with support $\left[\underline{p}^{*}, \bar{p}^{*}\right]$, where $\bar{p}^{*}=\check{p}$ and $\underline{p}^{*}$ is the solution to

$$
\frac{(1-\alpha) z_{1}^{*}+2 \alpha d^{*}\left(\underline{p}^{*}\right)}{(1-\alpha) d^{*}\left(\bar{p}^{*}\right)}=\frac{\left(\bar{p}^{*}-c\right) \underline{p}^{*}}{\left(\underline{p}^{*}-c\right) \bar{p}^{*}} .
$$

Since $Z_{0}^{*}<Z_{1}^{*}$, we have $\bar{p}^{*}\left(Z_{0}^{*}\right)=\bar{p}^{*}\left(Z_{1}^{*}\right)=\bar{p}^{*}, \underline{p}^{*}\left(Z_{1}^{*}\right)<\underline{p}^{*}\left(Z_{0}^{*}\right), \tilde{p}\left(z_{11}^{*}\right)<\tilde{p}\left(z_{10}^{*}\right)$, and $\tilde{p}\left(z_{21}^{*}\right)<$ $\tilde{p}\left(z_{20}^{*}\right)$. It is also straightforward to verify that given $\alpha$ and $F$, for $Z_{i}^{*}=\left(z_{1 i}^{*}, z_{2 i}^{*}\right), z_{1 i}^{*}<z_{2 i}^{*}$, for $i=0,1$. For $p \geq \tilde{p}\left(z_{10}^{*}\right), F\left(p ; Z_{0}^{*}\right)=F\left(p ; Z_{1}^{*}\right)$. For $p \in\left[\tilde{p}\left(z_{11}^{*}\right), \tilde{p}\left(z_{10}^{*}\right)\right]$, then $F\left(p ; Z_{0}^{*}\right)<$ $F\left(p ; Z_{1}^{*}\right)$ since $z_{10}^{*}<d^{*}(p)$. For $p \in\left[\underline{p}^{*}\left(Z_{0}^{*}\right), \tilde{p}\left(z_{11}^{*}\right)\right]$, we also have $F\left(p ; Z_{0}^{*}\right)<F\left(p ; Z_{1}^{*}\right)$ because $z_{10}^{*}<z_{11}^{*}$. As for $p \in\left[\underline{p}^{*}\left(Z_{1}^{*}\right), \underline{p}^{*}\left(Z_{0}^{*}\right)\right]$, we still have $F\left(p ; Z_{0}^{*}\right)=0<F\left(p ; Z_{1}^{*}\right)$. For $p \leq \underline{p}^{*}\left(Z_{1}^{*}\right), F\left(p ; Z_{0}^{*}\right)=F\left(p ; Z_{1}^{*}\right)=0$. Hence, $F\left(p ; Z_{0}^{*}\right)$ first-order stochastically dominates $F\left(p ; Z_{1}^{*}\right)$. 
Third, consider the case $\left(\underline{z}^{*}, \underline{z}^{*}\right) \leq Z_{0}^{*}<Z_{1}^{*} \leq\left(\bar{z}^{*}, \bar{z}^{*}\right)$. The price distribution is

$$
F\left(p ; Z^{*}\right)= \begin{cases}1-\frac{1-\alpha}{2 \alpha}\left[\frac{d^{*}\left(\bar{p}^{*}\right)\left(\bar{p}^{*}-c\right) p}{d^{*}(p)(p-c) \bar{p}^{*}}-1\right] & \text { if } p \in\left[\tilde{p}\left(z_{1}^{*}\right), \bar{p}^{*}\right] \\ 1-\frac{1-\alpha}{2 \alpha}\left[\frac{d^{*}\left(\bar{p}^{*}\right)\left(\bar{p}^{*}-c\right) p}{d^{*}(p)(p-c) \bar{p}^{*}}-\frac{z_{1}^{*}}{d^{*}(p)}\right] & \text { if } p \in\left[\tilde{p}\left(z_{2}^{*}\right), \tilde{p}\left(z_{1}^{*}\right)\right] \\ 1-\frac{1-\alpha}{2 \alpha}\left[\frac{d^{*}\left(\bar{p}^{*}\right)\left(\bar{p}^{*}-c\right) p}{z_{2}^{*}(p-c) \bar{p}^{*}}-\frac{z_{1}^{*}}{z_{2}^{*}}\right] & \text { if } p \in\left[\underline{p}^{*}, \tilde{p}\left(z_{2}^{*}\right)\right]\end{cases}
$$

with support $\left[\underline{p}^{*}, \bar{p}^{*}\right]$, where $\bar{p}^{*}=\check{p}$ and $\underline{p}^{*}$ is the solution to

$$
\frac{(1-\alpha) z_{1}^{*}+2 \alpha z_{2}^{*}}{(1-\alpha) d^{*}\left(\bar{p}^{*}\right)}=\frac{\left(\bar{p}^{*}-c\right) \underline{p}^{*}}{\left(\underline{p}^{*}-c\right) \bar{p}^{*}}
$$

Since $Z_{0}^{*}<Z_{1}^{*}$, we have $\bar{p}^{*}\left(Z_{0}^{*}\right)=\bar{p}^{*}\left(Z_{1}^{*}\right)=\bar{p}^{*}, \underline{p}^{*}\left(Z_{1}^{*}\right)<\underline{p}^{*}\left(Z_{0}^{*}\right), \tilde{p}\left(z_{11}^{*}\right)<\tilde{p}\left(z_{10}^{*}\right)$, and $\tilde{p}\left(z_{21}^{*}\right)<\tilde{p}\left(z_{20}^{*}\right)$. There are two possibilities regarding the relationship between $\tilde{p}\left(z_{11}^{*}\right)$ and $\tilde{p}\left(z_{20}^{*}\right)$, and then we need to discuss two different situations, $\tilde{p}\left(z_{21}^{*}\right)<\tilde{p}\left(z_{20}^{*}\right)<\tilde{p}\left(z_{11}^{*}\right)<\tilde{p}\left(z_{10}^{*}\right)$ and $\tilde{p}\left(z_{21}^{*}\right)<\tilde{p}\left(z_{11}^{*}\right)<\tilde{p}\left(z_{20}^{*}\right)<\tilde{p}\left(z_{10}^{*}\right)$. We discuss the first situation in the following and the second situation can be verified similarly. For $p \geq \tilde{p}\left(z_{10}^{*}\right), F\left(p ; Z_{0}^{*}\right)=F\left(p ; Z_{1}^{*}\right)$. For $p \in\left[\tilde{p}\left(z_{11}^{*}\right), \tilde{p}\left(z_{10}^{*}\right)\right], F\left(p ; Z_{0}^{*}\right)<F\left(p ; Z_{1}^{*}\right)$ since $z_{10}^{*}<d^{*}(p)$. For $p \in\left[\tilde{p}\left(z_{20}^{*}\right), \tilde{p}\left(z_{11}^{*}\right)\right]$, $F\left(p ; Z_{0}^{*}\right)<F\left(p ; Z_{1}^{*}\right)$ because $z_{10}^{*}<z_{11}^{*}$. For $p \in\left[\tilde{p}\left(z_{21}^{*}\right), \tilde{p}\left(z_{20}^{*}\right)\right], F\left(p ; Z_{0}^{*}\right)<F\left(p ; Z_{1}^{*}\right)$ since $z_{10}^{*} / z_{20}^{*}<z_{11}^{*} / d^{*}(p)$. For $p \in\left[\underline{p}^{*}\left(Z_{0}^{*}\right), \tilde{p}\left(z_{21}^{*}\right)\right]$, because $z_{10}^{*}<z_{11}^{*}$ and $z_{20}^{*}<z_{21}^{*}, F\left(p ; Z_{0}^{*}\right)<$ $F\left(p ; Z_{1}^{*}\right)$. When $p \in\left[\underline{p}^{*}\left(Z_{1}^{*}\right), \underline{p}^{*}\left(Z_{0}^{*}\right)\right], F\left(p ; Z_{0}^{*}\right)=0<F\left(p ; Z_{1}^{*}\right)$. Hence, $F\left(p ; Z_{0}^{*}\right)$ first-order stochastically dominates $F\left(p ; Z_{1}^{*}\right)$ in this case.

Finally, consider the case $z_{1 i}^{*} \leq \underline{z}^{*} \leq z_{2 i}^{*} \leq \bar{z}^{*}$ for $i=0,1$ and $Z_{0}^{*}<Z_{1}^{*}$, which is the same as the case $z_{1 i}^{*} \leq z_{2 i}^{*} \leq \underline{z}^{*} \leq \bar{z}^{*}$. The price distribution is

$$
F\left(p ; Z^{*}\right)= \begin{cases}1-\frac{1-\alpha}{2 \alpha}\left[\frac{z_{1}^{*}\left(\bar{p}^{*}-c\right) p}{d^{*}(p)(p-c) \bar{p}^{*}}-\frac{z_{1}^{*}}{d^{*}(p)}\right] & \text { if } p \in\left[\tilde{p}\left(z_{2}^{*}\right), \bar{p}^{*}\right] \\ 1-\frac{1-\alpha}{2 \alpha}\left[\frac{z_{1}^{*}\left(\bar{p}^{*}-c\right) p}{z_{2}^{*}(p-c) \bar{p}^{*}}-\frac{z_{1}^{*}}{z_{2}^{*}}\right] & \text { if } p \in\left[\underline{p}^{*}, \tilde{p}\left(z_{2}^{*}\right)\right]\end{cases}
$$

with support $\left[\underline{p}^{*}, \bar{p}^{*}\right]$, where $\bar{p}^{*}=\tilde{p}\left(z_{1}^{*}\right)$ and $\underline{p}^{*}$ is the solution to

$$
1+\frac{2 \alpha z_{2}^{*}}{(1-\alpha) z_{1}^{*}}=\frac{\left(\bar{p}^{*}-c\right) \underline{p}^{*}}{\left(\underline{p}^{*}-c\right) \bar{p}^{*}}
$$

Since $Z_{0}^{*}<Z_{1}^{*}$, we have $\bar{p}^{*}\left(Z_{1}^{*}\right)=\tilde{p}\left(z_{11}^{*}\right)<\tilde{p}\left(z_{10}^{*}\right)=\bar{p}^{*}\left(Z_{0}^{*}\right), \underline{p}^{*}\left(Z_{1}^{*}\right)<\underline{p}^{*}\left(Z_{0}^{*}\right)$, and $\tilde{p}\left(z_{21}^{*}\right)<$ $\tilde{p}\left(z_{20}^{*}\right)$. For $p \in\left[\bar{p}^{*}\left(Z_{1}^{*}\right), \bar{p}^{*}\left(Z_{0}^{*}\right)\right], F\left(p ; Z_{0}^{*}\right)<F\left(p ; Z_{1}^{*}\right)=1$. For $p \in\left[\tilde{p}\left(z_{20}^{*}\right), \bar{p}^{*}\left(Z_{1}^{*}\right)\right]$, we can verify that $F\left(p ; Z_{0}^{*}\right)<F\left(p ; Z_{1}^{*}\right)$ because $z_{10}^{*}<z_{11}^{*}$. For $p \in\left[\tilde{p}\left(z_{21}^{*}\right)<\tilde{p}\left(z_{20}^{*}\right)\right], F\left(p ; Z_{0}^{*}\right)<$ $F\left(p ; Z_{1}^{*}\right)$ since $z_{10}^{*} / z_{20}^{*}<z_{11}^{*} / d^{*}(p)$. For $p \in\left[\underline{p}^{*}\left(Z_{0}^{*}\right), \tilde{p}\left(z_{21}^{*}\right)\right], F\left(p ; Z_{0}^{*}\right)<F\left(p ; Z_{1}^{*}\right)$ since $z_{10}^{*}<z_{11}^{*}$ and $z_{20}^{*}<z_{21}^{*}$. For $p \in\left[\underline{p}^{*}\left(Z_{1}^{*}\right), \underline{p}^{*}\left(Z_{0}^{*}\right)\right], F\left(p ; Z_{0}^{*}\right)=0<F\left(p ; Z_{1}^{*}\right)$. Therefore, 
$F\left(p ; Z_{0}^{*}\right)$ first-order stochastically dominates $F\left(p ; Z_{1}^{*}\right)$ again in this case and we have proved Claim 1.

Claim 2 Given $\alpha$ and $F\left(p ; z_{1}^{*}, z_{2}^{*}\right)$, let the unique solution for $z_{1}$ and $z_{2}$ in household's $C M$ problem be $z_{i}=\varphi_{i}\left(z_{1}^{*}, z_{2}^{*}\right)$ for $i=1,2$. Then, $\varphi_{i}$ have the following properties:

(i) $\forall z_{i 0}^{*}$, $z_{i 1}^{*}$ such that $0<z_{i 0}^{*}<z_{i 1}^{*} \leq \bar{z}^{*}, \varphi_{i}\left(z_{10}^{*}, z_{20}^{*}\right) \leq \varphi_{i}\left(z_{11}^{*}, z_{21}^{*}\right)$, for $i=1,2$.

(ii) $\forall z_{i 0}^{*}, z_{i 1}^{*}$ such that $\bar{z}^{*} \leq z_{i 0}^{*}<z_{i 1}^{*}, \varphi_{i}\left(z_{10}^{*}, z_{20}^{*}\right) \leq \varphi_{i}\left(z_{11}^{*}, z_{21}^{*}\right)$, for $i=1,2$.

(iii) $\forall z_{i}^{*}>0, \varphi_{i}\left(z_{1}^{*}, z_{2}^{*}\right) \in\left[\underline{\varphi}_{i}, \bar{\varphi}\right)$, where $\bar{\varphi}=\bar{z}^{*}$ and $\underline{\varphi}_{i}>0$, for $i=1,2$.

Proof. Given the measure of type-2 buyers $\alpha$ and the price distribution $F\left(p ; z_{1}^{*}, z_{2}^{*}\right)$, the equilibrium conditions for real balances $z_{1}$ and $z_{2}$ are

$$
\int_{\underline{p}\left(z_{1}^{*}, z_{2}^{*}\right)}^{\tilde{p}\left(z_{1}\right)}\left[u^{\prime}\left(\frac{z_{1}}{p}\right) \frac{1}{p}-1\right] \mathrm{d} F\left(p ; z_{1}^{*}, z_{2}^{*}\right)=i
$$

and

$$
\int_{\underline{p}\left(z_{1}^{*}, z_{2}^{*}\right)}^{\tilde{p}\left(z_{2}\right)}\left[u^{\prime}\left(\frac{z_{2}}{p}\right) \frac{1}{p}-1\right] \mathrm{d}\left[1-\left(1-F\left(p ; z_{1}^{*}, z_{2}^{*}\right)\right)^{2}\right]=i .
$$

Let $\chi_{1}\left(z_{1} ; z_{1}^{*}, z_{2}^{*}\right)$ denote the left-hand side of $(30)$ and $\chi_{2}\left(z_{2} ; z_{1}^{*}, z_{2}^{*}\right)$ denote the left-hand side of (31). One can easily show that

$$
\begin{aligned}
& \lim _{z_{1} \rightarrow 0} \chi_{1}\left(z_{1} ; z_{1}^{*}, z_{2}^{*}\right)=\infty \\
& \lim _{z_{2} \rightarrow 0} \chi_{2}\left(z_{2} ; z_{1}^{*}, z_{2}^{*}\right)=\infty
\end{aligned}
$$

and $\chi_{i}\left(z_{i} ; z_{1}^{*}, z_{2}^{*}\right)$ strictly decreases in $z_{i}, \forall z_{i} \in\left(0, \hat{z}_{i}\right)$ where $\tilde{p}\left(\hat{z}_{i}\right)=\underline{p}\left(z_{1}^{*}, z_{2}^{*}\right)$, for $i=1,2$. Also notice that $\chi_{i}\left(z_{i} ; z_{1}^{*}, z_{2}^{*}\right)=0, \forall z_{i} \geq \hat{z}_{i}$. Hence, there is a unique solution $z_{1}=\varphi_{1}\left(z_{1}^{*}, z_{2}^{*}\right)$ to (30) and a unique solution $z_{2}=\varphi_{2}\left(z_{1}^{*}, z_{2}^{*}\right)$ to (31) with $\varphi_{i}\left(z_{1}^{*}, z_{2}^{*}\right) \in\left(0, \hat{z}_{i}\right)$, for $i=1,2$.

Consider $0<Z_{0}^{*}<Z_{1}^{*} \leq\left(\bar{z}^{*}, \bar{z}^{*}\right)$. According to Claim $1, F\left(p ; Z_{0}^{*}\right)$ first-order stochastically dominates $F\left(p ; Z_{1}^{*}\right)$, and then $1-\left(1-F\left(p ; Z_{0}^{*}\right)\right)^{2}$ first-order stochastically dominates $1-\left(1-F\left(p ; Z_{1}^{*}\right)\right)^{2}$. Since $u^{\prime}\left(z_{i} / p\right) / p-1$ decreases in $z_{i}$ for $i=1,2$, we have $\chi_{1}\left(z_{1} ; Z_{0}^{*}\right) \leq \chi_{1}\left(z_{1} ; Z_{1}^{*}\right)$ and $\chi_{2}\left(z_{2} ; Z_{0}^{*}\right) \leq \chi_{2}\left(z_{2} ; Z_{0}^{*}\right)$, which implies $\varphi_{1}\left(Z_{0}^{*}\right)<\varphi_{1}\left(Z_{1}^{*}\right)$ and $\varphi_{2}\left(Z_{0}^{*}\right)<\varphi_{2}\left(Z_{1}^{*}\right)$. One can also easily verify that $\varphi_{i}\left(Z_{0}^{*}\right) \geq \underline{\varphi}_{i}$ for some $\underline{\varphi}_{i}>0, i=1,2$.

Finally, consider the case $\left(\bar{z}^{*}, \bar{z}^{*}\right) \leq Z_{0}^{*}<Z_{1}^{*}$. According to Claim $1, F\left(p ; Z_{0}^{*}\right)=F\left(p ; Z_{1}^{*}\right)$ and $1-\left(1-F\left(p ; Z_{0}^{*}\right)\right)^{2}=1-\left(1-F\left(p ; Z_{1}^{*}\right)\right)^{2}$ Consequently, we have $\chi_{i}\left(z_{i} ; Z_{0}^{*}\right) \leq \chi_{i}\left(z_{i} ; Z_{1}^{*}\right)$, and hence $\varphi_{i}\left(Z_{0}^{*}\right)=\varphi_{i}\left(Z_{1}^{*}\right)<\bar{z}^{*}$, for $i=1,2$.

Claim 3 Given $\alpha \in(0,1)$, there exists $z_{i}^{*} \in\left[\underline{\varphi}_{i}, \bar{\varphi}\right)$ such that $\varphi_{i}\left(z_{1}^{*}, z_{2}^{*}\right)=z_{i}^{*}$, for $i=1,2$. 
Proof. Define $\varphi\left(z_{1}^{*}, z_{2}^{*}\right)=\left(z_{1}, z_{2}\right)=\left(\varphi_{1}\left(z_{1}^{*}, z_{2}^{*}\right), \varphi_{2}\left(z_{1}^{*}, z_{2}^{*}\right)\right)$. Claim (2) then implies that $\varphi\left(z_{1}^{*}, z_{2}^{*}\right)$ is increasing in both arguments and $\varphi\left(z_{1}^{*}, z_{2}^{*}\right) \in\left[\underline{\varphi}_{1}, \bar{\varphi}\right) \times\left[\underline{\varphi}_{2}, \bar{\varphi}\right), \forall\left(z_{1}^{*}, z_{2}^{*}\right) \in\left[\underline{\varphi}_{1}, \bar{\varphi}\right] \times$ $\left[\underline{\varphi}_{2}, \bar{\varphi}\right]$. By Tarski's fixed point theorem, there exists $\left(z_{1}^{*}, z_{2}^{*}\right) \in\left[\underline{\varphi}_{1}, \bar{\varphi}\right) \times\left[\underline{\varphi}_{2}, \bar{\varphi}\right)$ such that $\left(z_{1}^{*}, z_{2}^{*}\right)=\varphi\left(z_{1}^{*}, z_{2}^{*}\right)$, i.e. $z_{1}^{*}=\varphi_{1}\left(z_{1}^{*}, z_{2}^{*}\right)$ and $z_{2}^{*}=\varphi_{2}\left(z_{1}^{*}, z_{2}^{*}\right)$. This proves existence. Claim (2) also implies that $\forall z_{i}^{*} \leq \varphi_{i}, \varphi_{i}\left(z_{1}^{*}, z_{2}^{*}\right) \geq \varphi_{i}$, and $\forall z_{i}^{*} \geq \bar{\varphi}, \varphi_{i}\left(z_{1}^{*}, z_{2}^{*}\right)<\bar{\varphi}=\bar{z}^{*}$, for $i=1,2$. Therefore, if $z_{1}^{*}$ and $z_{2}^{*}$ satisfy $z_{1}^{*}=\varphi_{1}\left(z_{1}^{*}, z_{2}^{*}\right)$ and $z_{2}^{*}=\varphi_{2}\left(z_{1}^{*}, z_{2}^{*}\right)$, we must have $z_{1}^{*} \in\left[\underline{\varphi}_{1}, \bar{\varphi}\right)$ and $z_{2}^{*} \in\left[\underline{\varphi}_{2}, \bar{\varphi}\right)$.

Claim $4 \exists \bar{k}>0$ such that for $k \in(0, \bar{k})$, there exists $\alpha^{*} \in(0,1)$ such that $\Phi\left(\alpha^{*}\right)=k$.

Proof. Claim (3) implies that given $\alpha \in(0,1)$, we can find $z_{1}^{*}<z_{2}^{*}$, hence $\tilde{p}\left(z_{2}^{*}\right)<\tilde{p}\left(z_{1}^{*}\right)$ and $F^{*}=F\left(p ; z_{1}^{*}, z_{2}^{*}\right)$, that solve the household's problem and the firm's problem. Then, $\Phi(\alpha)$ can be defined as

$$
\begin{aligned}
\Phi(\alpha)= & \int_{\underline{p}^{*}}^{\bar{p}^{*}}\left[u\left(\frac{d^{*}\left(p ; z_{2}^{*}\right)}{p}\right)-d^{*}\left(p ; z_{2}^{*}\right)\right] \mathrm{d}\left[1-\left(1-F^{*}\right)^{2}\right] \\
& -\int_{\underline{p}^{*}}^{\bar{p}^{*}}\left[u\left(\frac{d^{*}\left(p ; z_{1}^{*}\right)}{p}\right)-d^{*}\left(p ; z_{1}^{*}\right)\right] \mathrm{d} F^{*}-i\left(z_{2}^{*}-z_{1}^{*}\right) .
\end{aligned}
$$

Notice that $F^{*}$ first-order stochastically dominates $1-\left(1-F^{*}\right)^{2}$ and $u\left(d^{*}\left(p ; z_{1}^{*}\right) / p\right)-d^{*}\left(p ; z_{1}^{*}\right)$ is decreasing in $p$, and then

$$
\int_{\underline{p}^{*}}^{\bar{p}^{*}}\left[u\left(\frac{d^{*}\left(p ; z_{1}^{*}\right)}{p}\right)-d^{*}\left(p ; z_{1}^{*}\right)\right] \mathrm{d}\left[1-\left(1-F^{*}\right)^{2}\right]>\int_{\underline{p}^{*}}^{\bar{p}^{*}}\left[u\left(\frac{d^{*}\left(p ; z_{1}^{*}\right)}{p}\right)-d^{*}\left(p ; z_{1}^{*}\right)\right] \mathrm{d} F^{*} .
$$

This implies that

$$
\begin{aligned}
\Phi(\alpha)> & \int_{\underline{p}^{*}}^{\bar{p}^{*}}\left[u\left(\frac{d^{*}\left(p ; z_{2}^{*}\right)}{p}\right)-d^{*}\left(p ; z_{2}^{*}\right)\right] \mathrm{d}\left[1-\left(1-F^{*}\right)^{2}\right] \\
& -\int_{\underline{p}^{*}}^{\bar{p}^{*}}\left[u\left(\frac{d^{*}\left(p ; z_{1}^{*}\right)}{p}\right)-d^{*}\left(p ; z_{1}^{*}\right)\right] \mathrm{d}\left[1-\left(1-F^{*}\right)^{2}\right]-i\left(z_{2}^{*}-z_{1}^{*}\right) \\
= & \int_{\underline{p}^{*}}^{\bar{p}^{*}}\left[u\left(\frac{d^{*}\left(p ; z_{2}^{*}\right)}{p}\right)-d^{*}\left(p ; z_{2}^{*}\right)-u\left(\frac{d^{*}\left(p ; z_{1}^{*}\right)}{p}\right)+d^{*}\left(p ; z_{1}^{*}\right)\right] \mathrm{d}\left[1-\left(1-F^{*}\right)^{2}\right] \\
& -i\left(z_{2}^{*}-z_{1}^{*}\right)
\end{aligned}
$$


Then, we plug in (31) and get

$$
\begin{aligned}
\Phi(\alpha)> & \int_{\underline{p}^{*}}^{\bar{p}^{*}}\left[u\left(\frac{d^{*}\left(p ; z_{2}^{*}\right)}{p}\right)-d^{*}\left(p ; z_{2}^{*}\right)-u\left(\frac{d^{*}\left(p ; z_{1}^{*}\right)}{p}\right)+d^{*}\left(p ; z_{1}^{*}\right)\right] \mathrm{d}\left[1-\left(1-F^{*}\right)^{2}\right] \\
& -\int_{\underline{p}^{*}}^{\tilde{p}\left(z_{2}^{*}\right)}\left[u^{\prime}\left(\frac{z_{2}^{*}}{p}\right) \frac{1}{p}-1\right]\left(z_{2}^{*}-z_{1}^{*}\right) \mathrm{d}\left[1-\left(1-F^{*}\right)^{2}\right] \\
> & \int_{\underline{p}^{*}}^{\tilde{p}\left(z_{2}^{*}\right)}\left[u\left(\frac{z_{2}^{*}}{p}\right)-z_{2}^{*}-u\left(\frac{z_{1}^{*}}{p}\right)+z_{1}^{*}\right] \mathrm{d}\left[1-\left(1-F^{*}\right)^{2}\right] \\
& -\int_{\underline{p}^{*}}^{\tilde{p}\left(z_{2}^{*}\right)}\left[u^{\prime}\left(\frac{z_{2}^{*}}{p}\right) \frac{1}{p}-1\right]\left(z_{2}^{*}-z_{1}^{*}\right) \mathrm{d}\left[1-\left(1-F^{*}\right)^{2}\right] .
\end{aligned}
$$

Since $u(z / p)-z$ is concave in $z$, for $z_{1}^{*}<z_{2}^{*}$, we have

$$
u\left(\frac{z_{2}^{*}}{p}\right)-z_{2}^{*}-\left[u\left(\frac{z_{1}^{*}}{p}\right)-z_{1}^{*}\right] \geq\left(z_{2}^{*}-z_{1}^{*}\right)\left[u^{\prime}\left(\frac{z_{2}^{*}}{p}\right) \frac{1}{p}-1\right] .
$$

The above equation then implies $\Phi(\alpha)>0$ for $\alpha \in(0,1)$.

Since $\Phi(\alpha)$ is a continuous function defined on $[0,1]$, it must attain a maximum value, denoted as $\bar{k}$. On the other hand, it is straightforward to verify that $\Phi(0)=0$ and $\Phi(1)=0$, then $\exists \tilde{\alpha} \in(0,1)$ such that $\Phi(\tilde{\alpha})=\bar{k}$. Therefore, for $k \in(0, \bar{k})$, there exists $\alpha^{*} \in(0,1)$ such that $\Phi\left(\alpha^{*}\right)-k=0$. 


\section{Appendix B: Stochastic Money Supply}

We study the welfare cost of inflation fluctuations by considering a stochastic money supply process. Suppose the money supply follows $M_{t+1}=\gamma_{t} M_{t}$ and $\gamma_{t}$ is independent and identically distributed across time, satisfying $1 / E\left(\gamma_{t}^{-1}\right)>\beta$. New money is injected or destroyed in the CM. Agents learn about the money growth rate at the beginning of period $t$.

In order to study monetary shocks, we need to modify the model. Since sellers do not receive transfer payments in the $\mathrm{CM}$ or carry money into the $\mathrm{DM}$, their optimization problem in the CM is the same as in Section 3.2. In the DM, the shock realizes before they post prices. Sellers actually face no uncertainty and solve the same profit maximizing problem. However, because buyers need to carry money from the CM to the next DM to make purchases, they now face a different optimization problem. We can rewrite a type-1 buyer's CM value function as

$$
\begin{gathered}
W_{1}^{b}(z)=\max _{x_{1}, h_{1}, \hat{z}_{1}}\left\{v\left(x_{1}\right)-h_{1}+\int \beta V_{1}^{b}\left(\frac{\hat{z}_{1}}{\gamma}\right) \mathrm{d} \Gamma\right\} \\
\text { s.t. } h_{1}+z+T=x_{1}+\hat{z}_{1}
\end{gathered}
$$

Since $\gamma$ realizes in the beginning of the next period, buyers cannot choose the value of their real balance in the next DM. Instead, they now choose the real balance to bring to the next period $\hat{z}_{1}$. Its value becomes $\hat{z}_{1} / \gamma$ in the next DM, depending on the realized monetary shock $\gamma$, and hence the production and consumption in the DM will also be affected. In the stationary equilibrium, type- 1 buyers choose the same real balance today before $\gamma$ realizes. Similarly, a type-2 buyer now faces the following problem in the CM.

$$
\begin{gathered}
W_{2}^{b}(z)=\max _{x_{2}, h_{2}, \hat{z}_{2}}\left\{v\left(x_{2}\right)-h_{2}+\int \beta V_{2}^{b}\left(\frac{\hat{z}_{2}}{\gamma}\right) \mathrm{d} \Gamma\right\} \\
\text { s.t. } h_{2}+z+T=x_{2}+\hat{z}_{2}
\end{gathered}
$$

Turning to the DM, the value function of a type- 1 buyer $V_{1}^{b}\left(\hat{z}_{1} / \gamma\right)$ is given by

$$
V_{1}^{b}\left(\frac{\hat{z}_{1}}{\gamma}\right)=\int_{\underline{p}}^{\bar{p}}\left\{u\left(\frac{d^{*}\left(p ; \hat{z}_{1} / \gamma\right)}{p}\right)+W^{b}\left[\frac{\hat{z}_{1}}{\gamma}-d^{*}\left(p ; \frac{\hat{z}_{1}}{\gamma}\right)\right]\right\} \mathrm{d} F(p) .
$$

The buyer's optimal expenditure on the DM goods $d^{*}\left(p ; \hat{z}_{1} / \gamma\right)$ depends on his after-shock real balance $\hat{z}_{1} / \gamma$ and the transaction price $p$. After the buyer pays for the DM goods, he carries a real balance of $\hat{z}_{1} / \gamma-d^{*}\left(p ; \hat{z}_{1} / \gamma\right)$, and $W^{b}\left[\hat{z}_{1} / \gamma-d^{*}\left(p ; \hat{z}_{1} / \gamma\right)\right]$ represents the continuation 
value of entering the next CM. Similarly, a type-2 buyer's DM value function now becomes

$$
V_{2}^{b}\left(\frac{\hat{z}_{2}}{\gamma}\right)=\int_{\underline{p}}^{\bar{p}}\left\{u\left(\frac{d^{*}\left(p ; \hat{z}_{2} / \gamma\right)}{p}\right)+W^{b}\left[\frac{\hat{z}_{2}}{\gamma}-d^{*}\left(p ; \frac{\hat{z}_{2}}{\gamma}\right)\right]\right\} \mathrm{d}\left[1-(1-F(p))^{2}\right]-k .
$$

The previous results regarding the buyer's CM value functions still hold, and we can apply the linearity of $W^{b}(z)$ to rewrite (34) and (35) as

$$
V_{1}^{b}\left(\frac{\hat{z}_{1}}{\gamma}\right)=\int_{\underline{p}}^{\bar{p}}\left\{u\left(\frac{d^{*}\left(p ; \hat{z}_{1} / \gamma\right)}{p}\right)-d^{*}\left(p ; \frac{\hat{z}_{1}}{\gamma}\right)\right\} \mathrm{d} F(p)+W^{b}\left(\frac{\hat{z}_{1}}{\gamma}\right)
$$

and

$$
V_{2}^{b}\left(\frac{\hat{z}_{2}}{\gamma}\right)=\int_{\underline{p}}^{\bar{p}}\left\{u\left(\frac{d^{*}\left(p ; \hat{z}_{2} / \gamma\right)}{p}\right)-d^{*}\left(p ; \frac{\hat{z}_{2}}{\gamma}\right)\right\} \mathrm{d}\left[1-(1-F(p))^{2}\right]-k+W^{b}\left(\frac{\hat{z}_{2}}{\gamma}\right) .
$$

Notice that buyers face the same problem in the DM as before, but now the real value of their money holdings depends on the monetary shock $\gamma$, which they can only learn after entering the DM. Therefore, Lemma 1 and Lemma 2 still hold. After substituting (36) and (37) into (32) and (33), the type-1 and type-2 buyer's optimal real balance $\hat{z}_{1}^{*}$ and $\hat{z}_{2}^{*}$ are characterized by the following FOCs.

$$
\begin{gathered}
\frac{1}{\beta}=\int \frac{1}{\gamma}\left\{\int_{\underline{p}}^{\tilde{p}_{1}\left(\hat{z}_{1}^{*} / \gamma\right)}\left[u^{\prime}\left(\frac{\hat{z}_{1}^{*} / \gamma}{p}\right) \frac{1}{p}-1\right] \mathrm{d} F(p)+1\right\} \mathrm{d} \Gamma \\
\frac{1}{\beta}=\int \frac{1}{\gamma}\left\{\int_{\underline{p}}^{\tilde{p}_{2}\left(\hat{z}_{2}^{*} / \gamma\right)}\left[u^{\prime}\left(\frac{\hat{z}_{2}^{*} / \gamma}{p}\right) \frac{1}{p}-1\right] \mathrm{d}\left[1-(1-F(p))^{2}\right]+1\right\} \mathrm{d} \Gamma
\end{gathered}
$$

To compare (38) and (39) with the deterministic money supply case, we can use the noarbitrage condition, $\phi=E[\beta(1+i) \hat{\phi}]$, to derive the stochastic Fisher equation, $1+i=$ $1 / \beta E\left(\gamma^{-1}\right)$. Then, we can rewrite (38) and (39) as

$$
\begin{gathered}
i=\frac{\iint_{\underline{p}}^{\tilde{p}_{1}}\left(\hat{z}_{1}^{*} / \gamma\right)\left[u^{\prime}\left(\frac{\hat{z}_{1}^{*} / \gamma}{p}\right) \frac{1}{p}-1\right] \gamma^{-1} \mathrm{~d} F(p) \mathrm{d} \Gamma}{\int \gamma^{-1} \mathrm{~d} \Gamma}, \\
i=\frac{\iint_{\underline{p}}^{\tilde{p}_{2}\left(\hat{z}_{2}^{*} / \gamma\right)}\left[u^{\prime}\left(\frac{\hat{z}_{2}^{*} / \gamma}{p}\right) \frac{1}{p}-1\right] \gamma^{-1} \mathrm{~d}\left[1-(1-F(p))^{2}\right] \mathrm{d} \Gamma}{\int \gamma^{-1} \mathrm{~d} \Gamma} .
\end{gathered}
$$

These are the stochastic versions of (14) and (16). Given a price distribution $F$ and monetary shock $\gamma$, these two conditions can determine the constant real balance in SME. Both the gain and the cost of holding money are affected by the monetary shock. Finally, buyers choose to 
be type-1 or type-2, and in equilibrium the expected gain of observing an additional price $\Phi(\alpha)$ is equal to the search cost $k$, where $\Phi(\alpha)$ is defined as

$$
\begin{aligned}
\Phi(\alpha)= & \iint_{\underline{p}}^{\bar{p}}\left[u\left(\frac{d^{*}\left(p ; \hat{z}_{2}^{*} / \gamma\right)}{p}\right)-d^{*}\left(p ; \hat{z}_{2}^{*} / \gamma\right)\right] \mathrm{d}\left[1-(1-F(p))^{2}\right] \mathrm{d} \Gamma \\
& -\iint_{\underline{p}}^{\bar{p}}\left[u\left(\frac{d^{*}\left(p ; \hat{z}_{1}^{*} / \gamma\right)}{p}\right)-d^{*}\left(p ; \hat{z}_{1}^{*} / \gamma\right)\right] \mathrm{d} F(p) \mathrm{d} \Gamma+\int\left(\frac{1}{\gamma}-\frac{1}{\beta}\right)\left(\hat{z}_{2}^{*}-\hat{z}_{1}^{*}\right) \mathrm{d} \Gamma .
\end{aligned}
$$

We want to use the revised model to measure the welfare cost of inflation fluctuations during the sample period of 101 years. We follow Cooley and Hansen (1989) and assume that $\gamma$ follows a $\log$-normal distribution, i.e., $\log \gamma \sim \mathcal{N}\left(\mu_{\gamma}, \epsilon_{\gamma}\right)$. While the values of $\sigma, A$, and $k$ are taken from the baseline calibration, we use M1 data in the sample to directly estimate the mean $\mu_{\gamma}=0.053$ and the standard deviation $\epsilon_{\gamma}=0.065$. The welfare cost is measured in the same way as in Section 5. An economy with constant money supply is considered as the benchmark. We find that the welfare cost of inflation is worth $5.53 \%$ of consumption, which means a representative agent in the benchmark economy has to give up $5.53 \%$ of his consumption to be indifferent to the economy with stochastic money supply. Then, we reduce $\epsilon_{\gamma}$ to zero and apply the stochastic Fisher equation to adjust $\mu_{\gamma}$ to keep the nominal interest rate the same. We find that the welfare cost reduced by only $0.15 \%$ of consumption in the benchmark economy. To compare our findings with Lucas (1987), we also calculate the welfare gain of smoothing monetary shocks using the smooth economy with $\epsilon_{\gamma}=0$ as the benchmark, and find the value to be $0.18 \%$. Therefore, more than $97 \%$ of the welfare cost comes from the trend inflation, and inflation fluctuations only contribute less than $3 \%$ to the total cost.

Compared to Lucas (1987), we find a larger welfare gain of smoothing aggregate shocks. Both our estimated welfare cost of trend inflation and inflation fluctuations are larger than those found in Faig and $\mathrm{Li}$ (2009), which are $0.25 \%$ and $0.0003 \%$, respectively. In our model, the welfare gain of eliminating monetary shocks is still negligible compared to the trend, due to the following reasons. First, to match the statistics of empirical money demand, the calibrated $\sigma$ is small, and the cost function of the DM goods is assumed to be linear. Both factors contribute to a larger elasticity of DM goods and a larger tolerance to consumption fluctuations. If we were to increase $\sigma$ without changing the other parameters, the welfare gain of smoothing monetary shocks would go up. Second, money supply shocks only affect the monetary transactions in the DM, and the share of the DM goods in the total output is small, around 10\%. This limits the effect of aggregate shocks on total consumption. Therefore, although the interaction of different channels amplifies the effect of both trend inflation and inflation fluctuations on welfare, the former is still more important in a quantitative sense. 